University of Wisconsin Milwaukee

UWM Digital Commons

Theses and Dissertations

May 2018

\title{
Microgrid Reliability Evaluation Based on Condition-Dependent Failure Models of Power Electronic Devices
}

Qi Li

University of Wisconsin-Milwaukee

Follow this and additional works at: https://dc.uwm.edu/etd

Part of the Electrical and Electronics Commons

\section{Recommended Citation}

Li, Qi, "Microgrid Reliability Evaluation Based on Condition-Dependent Failure Models of Power Electronic Devices" (2018). Theses and Dissertations. 1865.

https://dc.uwm.edu/etd/1865

This Thesis is brought to you for free and open access by UWM Digital Commons. It has been accepted for inclusion in Theses and Dissertations by an authorized administrator of UWM Digital Commons. For more information, please contact open-access@uwm.edu. 


\title{
MICROGRID RELIABILITY EVALUATION BASED ON CONDITION-DEPENDENT FAILURE MODELS OF POWER ELECTRONIC DEVICES
}

\author{
by \\ Qi Li \\ A Thesis Submitted in \\ Partial Fulfillment of the \\ Requirements for the Degree of \\ Master of Science \\ in Engineering
}

at

The University of Wisconsin-Milwaukee

May 2018 


\section{ABSTRACT \\ MICROGRID RELIABILITY EVALUATION BASED ON CONDITION-DEPENDENT FAILURE MODELS OF POWER ELECTRONIC DEVICES \\ by \\ Qi Li}

The University of Wisconsin-Milwaukee, 2018

Under the Supervision of Dr. Lingfeng Wang

Microgrid, a distributed energy system consisting of distributed energy and loads, aim $s$ to ensure reliable and affordable energy security in urban and rural communities. With the growing global energy need and the emerging threat of climate change, green renewa ble energy is becoming a new favorite in the field of power generation. Microgrids have rec eived wide spread attention and application for their minimizing carbon dioxide and gree nhouse gas emissions. Microgrids do so by maximizing clean local energy generation as well as reducing the stress of the transmission and distribution system.

With the use of renewable energy, the reliability performance of microgrids becomes an issue because many renewable energy sources are intermittent. As power electronics increasingly serve as interfaces for renewable energy integration in microgrids, the reliable performance of power electronics plays an important role in microgrid reliability. In recent years, although the reliability of microgrid and power electronics has been studied, most of the research was limited to the reliability evaluation on the long-term planning timescale. However, the operational reliability evaluation considering power electronic influence was rarely studied.

Power electronic devices such as converters are important parts of the microgrid system. The constant failure rate of converters has been widely used in power system planning. It has proved to be useful for calculating long-term or medium-term average reliability indices. However, 
under different operating conditions, the average failure rate cannot fully represent the failure rate of the component.

In this thesis, a converter real-time failure model in different micro-sources was built and tested. These models were applied to an 11-node microgrid test system to calculate the operating reliability indices under different situations. Then, the sensitivity analysis was carried out, and the influence of various factors was evaluated.

The converter real-time failure model is built based on the power losses of power electronics caused by the variation of the weather data (wind speed, ambient temperature, and illumination). To calculate the availability for test systems, systems were simplified to several sub-systems according to the power flow. By using the reliability block diagram (RBD) method and combining with the real-time availability of the converter, each sub-system's hourly availability was calculated. In the simulation, the system availability considering the influence of power electronics was calculated and a comparison was made with the system availability without considering the influence of power electronics. To calculate operational reliability indices, a short-term outage model was applied and varied cases were used to test the influencing factor. The sensitivity analyses demonstrated the influence of seasons, wind turbine parameters and meteorological conditions.

According to the simulation results, the reliability performance of the system can be more accurately reflected by these condition-dependent models. The ambient temperature is the main affecting factor for wind turbines and the illumination is the most important factor for photovoltaic arrays. The availability of subsystems varies significantly due to the different 
operating environments. The studies also indicated that the number and type of micro-sources in microgrid have great influence on the reliability indices of the overall system. The results of one year's simulation illustrate that the reliability of the system has a certain seasonality. And it also shows the dependence of operational reliability on factors such as wind turbine parameters, system topology as well as local meteorological conditions. 
(C) Copyright by Qi Li, 2018

All Rights Reserved 


\section{TABLE OF CONTENTS}

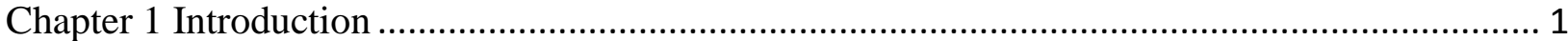

$1.1 \quad$ Research Background ............................................................................................ 1

1.1.1 Micro-grid system and main components ……………..................................... 1

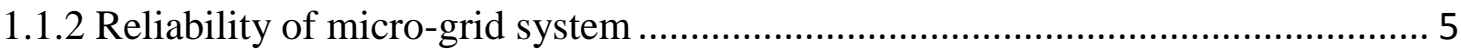

1.2 Reliability Evaluation model of power electronic systems............................................ 6

1.2.1 Component-Level Reliability Models.............................................................. 7

1.2.2. System or Subsystem-Level Reliability Models for micro-grid Systems............. 7

1.3 Research Objective and Thesis Layout ................................................................ 12

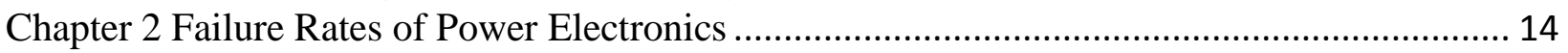

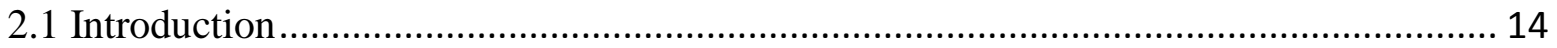

2.2 Model Establishment ......................................................................................... 14

2.2.1 Output Power of Renewable Energy Resources ............................................... 15

2.2.2. Calculating the Power Loss of Converter ........................................................ 17

2.2.3. Calculating Failure Rates of Power Electronic Modules .................................... 19

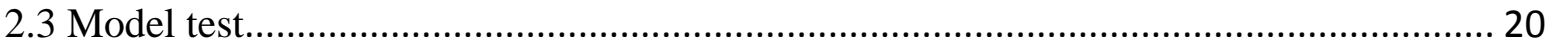

2.4 Conclusion and Future work ................................................................................ 24

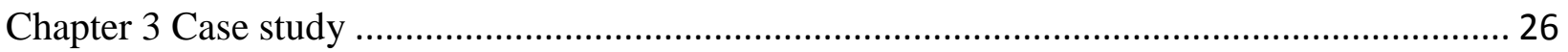

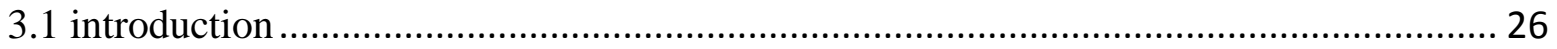

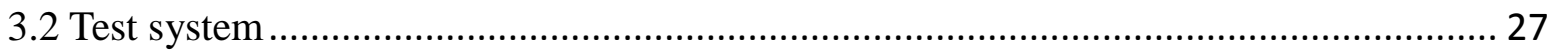

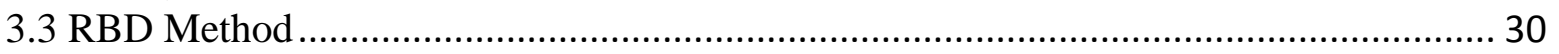

3.4 The short-term model........................................................................................ 38

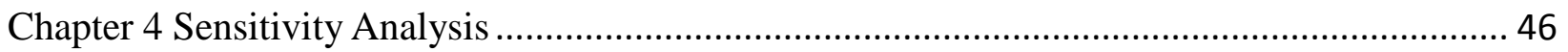

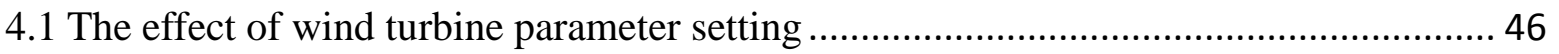

4.2 Yearly calculation and seasonal characteristics .......................................................... 48

4.3 The effect of meteorological condition ................................................................... 52

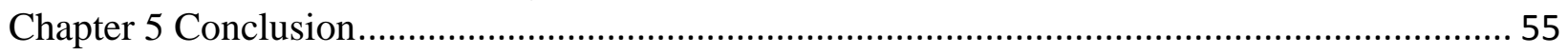

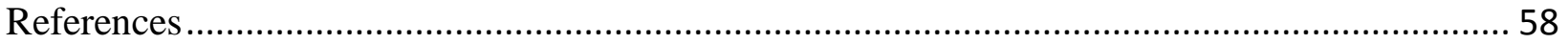




\section{LIST OF FIGURES}

Figure 1- 1 Micro-grid infrastructure .........................................................2

Figure 1-2 Power electronic interface for the wind turbine ............................... 3

Figure 1-3 Power electronic interface for the battery or PV array...................... 4

Figure 1-4 Illustration of the two-level converter ........................................

Figure 1-5 A simple RBD example ..................................................... 8

Figure 1-6 A simple fault tree diagram example.......................................... 10

Figure 2-1 Real-time converter outage model ............................................. 15

Figure 2-2 Meteorological conditions during the day in summer Milwaukee.....21

Figure 2-3 Real-time PV power output.....................................................2

Figure 2-4 Real-time wind power output................................................ 21

Figure 2-5 Real-time converter failure rate of PV .......................................22

Figure 2-6 Real-time converter failure rate of wind turbine.............................23

Figure 2-7 The failure rate of wind converter and its influence factors .............23

Figure 2- 8 The failure rate of PV converter and its influence factors ...............24

Figure 3-1 The flow chart to evaluate the reliability of Microgrid ....................22

Figure 3-2 The microgrid network used in simulation ................................22

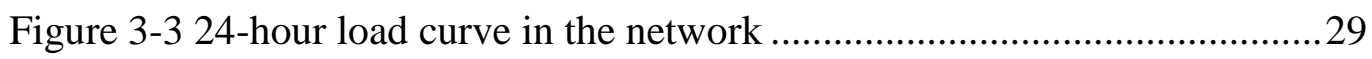

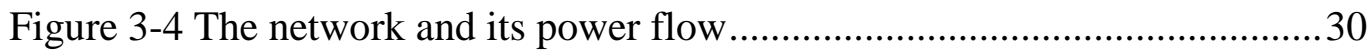

Figure 3-5 Micro-grid diagram for supporting load1,3,4 .............................. 31

Figure 3-6 RBD of the micro-grid to support load1,3,4 ................................ 31 
Figure 3-7 Micro-grid diagram for supporting load 5 ................................. 31

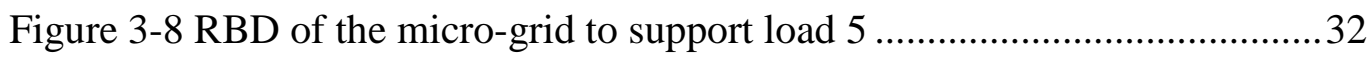

Figure 3-9 Micro-grid diagram for supporting load 6 .................................. 32

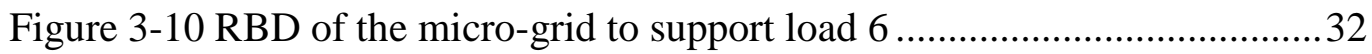

Figure 3-11 Micro-grid diagram for supporting load 7,8,9......................... 32

Figure 3-12 RBD of the micro-grid to support load 7,8,9 ...............................33

Figure 3-13 Micro-grid diagram for supporting load 10,11,12 ...................... 33

Figure 3-14 RBD of the micro-grid to support load 10,11,12 ........................33

Figure 3-15 Meteorological conditions during the day in summer Milwaukee...34

Figure 3-16 Availability for wind turbine converter .................................... 34

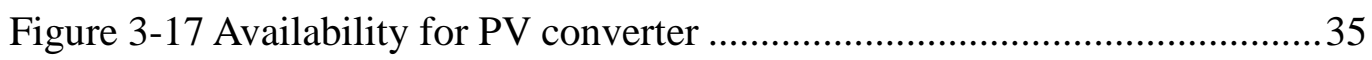

Figure 3-18 Availability for ES converter ................................................. 35

Figure 3-19 The load avaibility for different subsystems with the effect of power electronics 37

Figure 3-20 The load avaibility for different subsystems without the effect of power

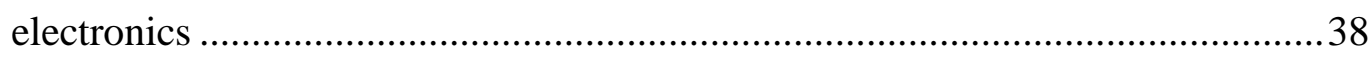

Figure 3-21 Flowchart of the evaluation procedure ....................................... 42

Figure 3- 22 Microgrid reliability indices of case 1 and case $2 \ldots \ldots \ldots \ldots \ldots \ldots . . . . . .43$

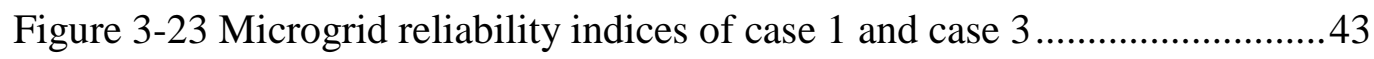

Figure 3-24 Microgrid reliability indices of case 1 and case $4 \ldots \ldots \ldots \ldots \ldots \ldots \ldots \ldots . . . . . . . . . . .44$

Figure 4-1 Average hourly wind generation ............................................ 46

Figure 4-2 Converter failure rate .......................................................... 47 
Figure 4-3 Average hourly wind generation .............................................. 47

Figure 4-4 Converter failure rate ....................................................... 48

Figure 4-5 Wind speed in Milwaukee, 2010 ................................................. 49

Figure 4-6 Ambient temperature in Milwaukee, 2010...................................49

Figure 4-7 Illumination in Milwaukee, 2010 .............................................49

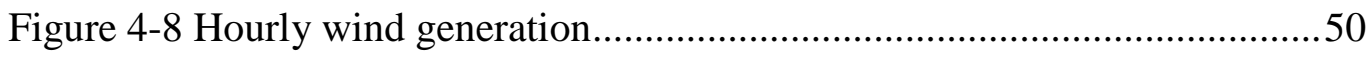

Figure 4-9 Hourly converter failure rate for wind turbine ...............................50

Figure 4-10 Hourly PV generation ........................................................ 51

Figure 4-11 Hourly converter failure rate for PV arrays..................................51

Figure 4-12 Hourly reliability indices for system .......................................52

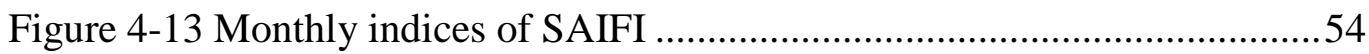




\section{LIST OF TABLES}

Table 2-1 Main parameters of the converter real-time failure model ................. 20

Table 3-1 parameters of main feeder .......................................................... 28

Table 3-2 Load parameters.................................................................. 28

Table 3-3 Location, capacity and reliability data of micro sources .....................30

Table 3-4 Four cases under different conditions ..........................................43

Table 3-5 Comparison of system reliability indices .......................................4 44 


\section{ACKNOWLEDGEMENTS}

The first person I want to express my gratitude is my thesis advisor Dr. Lingfeng Wang. Throughout my study here, whenever I turned to him, I would always get professional guidance on my research and other matters. Moreover, he always influenced me with his rigorous attitude, unwavering commitment, and broad knowledge in initiating and performing high-level research. Also, he is a kind and considerate mentor - during our group meetings, he often cared about the students' study and life here and gave us useful advice to adapt to the life in Milwaukee.

This work was supported in part by National Science Foundation Industry/University Cooperative Research Center on GRid-connected Advanced Power Electronic Systems (GRAPES), and in part by the Research Growth Initiative Program of University of Wisconsin-Milwaukee under Award 101X360, to which I am highly grateful.

I also want to appreciate my thesis committee: Dr. Yi Hu and Dr. Guangwu Xu as they spent time to take part in my defense and gave me comments on my thesis. They are also experts in their respective academic fields and their academic achievements set good examples for my future study.

In addition, I want to thank my labmates, Yunfan Zhang, Yitong Shen, and Zhaoxi Liu because they gave me much help and advice on my research with a lot of patience. I would also like to say thank you to my roommate Wen Zhong for her understanding and caring in life.

Last but not least, I want to thank my parents far in my homeland for their full support. 


\section{Chapter 1 Introduction}

\subsection{Research Background}

As climate change arouses people's attention, renewable energy sources (RES) are getting more widely used in the entire energy system. In this respect, smart grid technologies have been put forward to promote higher penetration of RES. Microgrids are the key components of the smart grids. Microgrids allow a variety of distributed energy resources (DER), such as distributed generation, especially renewable energy and energy storage system (ESSs). DERs are integrated into the distribution system, so as to eliminate or delay the need for distribution expansion [1].

A power grid accident in November 2006 caused a power failure in the European power grid. It affected 10 million people in Germany, France, Belgium, Spain and Austria. The main reason for this incident is the failure of the transmission system [2]. Because power system blackouts cause a large series of serious consequences in commercial, military and daily life, researchers are trying to improve the power grid resilience and design backup power systems which are able to meet the demand of the customers well.

Microgrids are getting more and more attention from all over the world. They are more reliable than traditional power grid, as they can function under natural disasters [3] because they can operate in both grid-connected and islanded modes.

\subsubsection{Micro-grid system and main components}

In many respects, microgrids are regarded as smaller versions of the traditional power grids. In literature [5], microgrids are configured as DC or AC grids which are connected to low or 
medium voltage distribution networks. Like current electrical grids, they consist of power generation, distribution, and controls such as voltage regulation and gear switching.

Below is a typical structure of microgrids which includes the integration of distributed generation system, energy storage system, loads and control technology with utility grid [3]. This creates an efficient and reliable microgrid system which can provide electricity even when the main power grid fails.

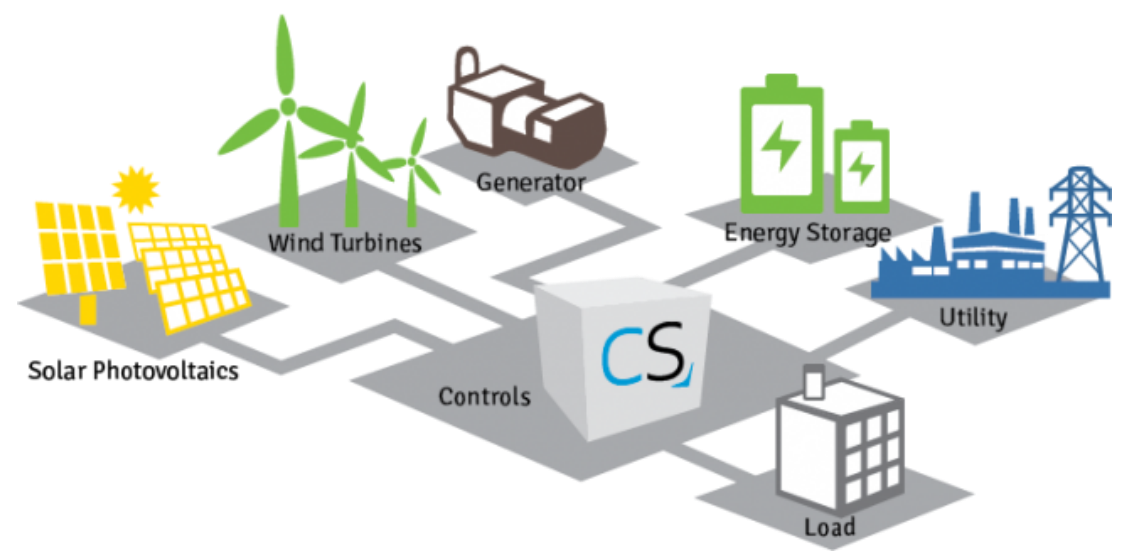

Figure 1-1 Micro-grid infrastructure[4]

There are usually both conventional generation as well as renewable energy sources integrated in microgrids, making an increase in efficiency and reductions in emission. Renewable energy sources such as solar, wind power, small hydro, geothermal and waste-to-energy, provide a closer proximity between power generation and power use. Conventional generation systems, such as diesel or natural gas generators, are used when clean energy systems can't meet the power demand or are highly intermittent.

In microgrids, energy storage can be regarded as either load or generation depending on its input and output power at the terminal. As an important part in microgrids, energy storage can 
ensure power quality, including frequency and voltage regulation, smooth the output of renewable energy sources, and provide backup power for the system. Energy storage can take many forms, such as batteries, super capacitors and hybrid energy storage systems, including all electric, pressure, gravity, flywheels, and heat storage technologies.

In microgrids, there are another important part called consumption. The consumption in microgrids simply refers to components that consume electrical energy including single equipment, lighting, building heating system, residential loads, commercial centers and so on. The power generated by the generating unit is supplied to the consumption through the transmission unit.

Both distributed generation systems and energy storage systems require power electronic converters to connect to consumption or the utility grid. The figures below show the basic configuration of the converter. Because the wind turbine generator produces AC power, it adopts a typical three-phase back-to-back converter, as shown in Figure 1-2. For the PV arrays and energy storage, a typical full bridge three-phase inverter is used because it produces DC power, as Figure 1-3 shows.

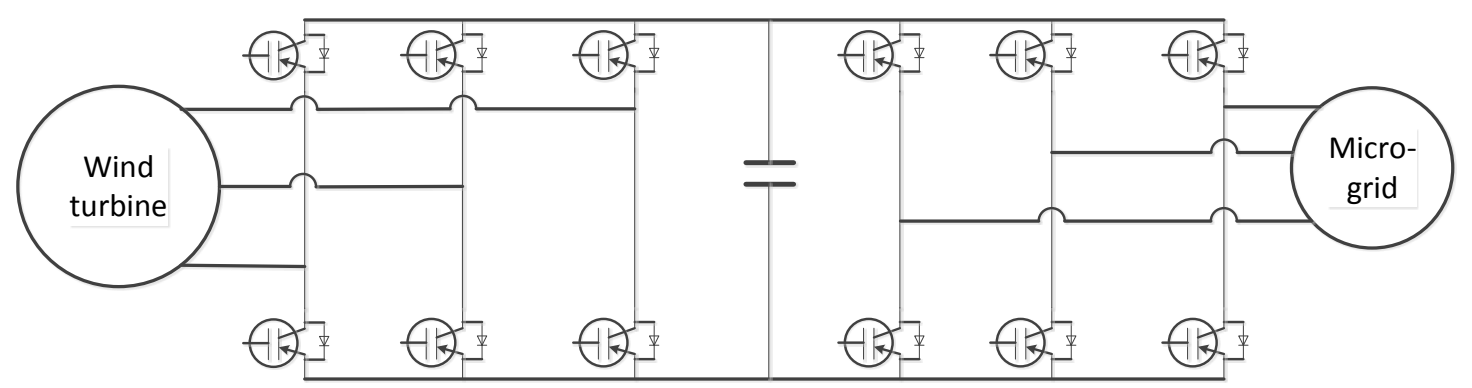

Figure 1-2 Power electronic interface for the wind turbine 


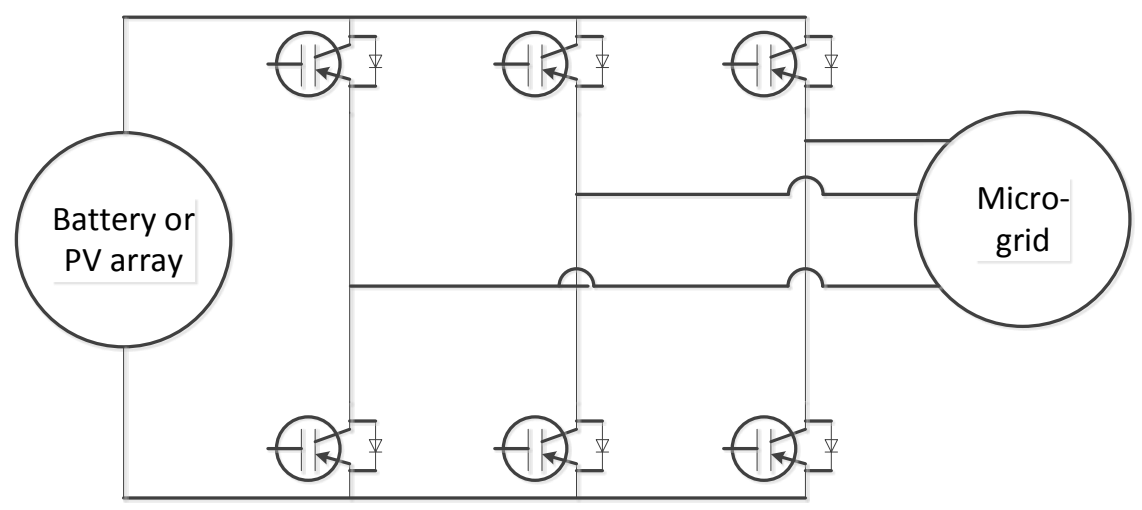

Figure 1-3 Power electronic interface for the battery or PV array

An specific illustration of each two-level converter is shown in Figure 1-4.

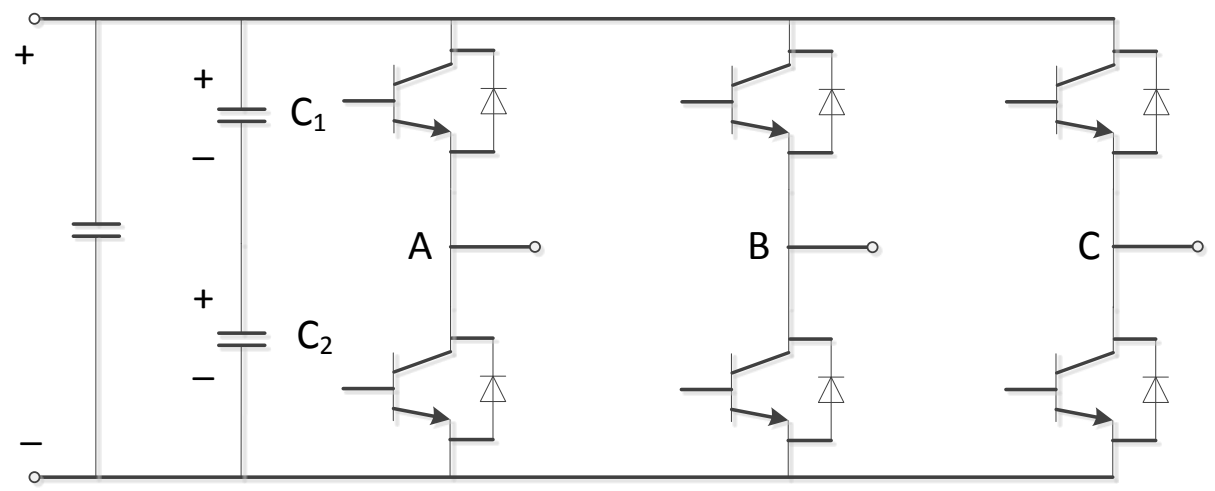

Figure 1-4 Illustration of the two-level converter

As shown above, each voltage source converter(VSC) includes 6 diodes and 6 IGBTs. For the wind turbine generator, the converter connects to the inverter through a capacitor which helps to limit the current. The filter on the $\mathrm{AC}$ side is used to reduce the harmonic content in the AC side.

During normal or peak use, or when the main power grid fails, the microgrid can operate independently and isolate the power generation nodes and the power load from interference without affecting the larger grid. When the power grid failure or power failure occurs, the microgrid can provide emergency power and can return the energy to the main power grid. 


\subsubsection{Reliability of micro-grid system}

The wide application of the microgrid can bring many benefits to the power system, such as power quality, reliability, and security for end users and operators of the power grid.

In recent years, many works have been done to evaluate the reliability of microgrids. In reference [7]-[9], most early researches focused on the influence of microgrids on the reliability of the distribution system. Since the feature of the structure, generation, and supply way is different between microgrid and traditional power system to a great extent, the reliability assessment of microgrids themselves gradually raise attention as well. In some references like [10], microgrid reliability is studied by considering the effect of varying photovoltaic and synchronous machine based distributed generation source type penetrations.

References [11],[12] and [13] not only consider the distribution generation in the evaluation of reliability for microgrids, they also consider the energy storage device especially in islanded modes where they can be treated as both generations and loads. In reference [14], a general reliability evaluation method based on Monte Carlo simulation is proposed to assess the reliability of both centralized Energy Management System (EMS) and distributed EMS in islanded microgrid.

The failure rates of components as well as system reliability indices can be influenced by varied operational states of generators, energy storages and protection systems in microgrids. Based on this phenomenon, some progress has been made in reference [15] or it proposes a short-term outage model under different operating states and environment conditions to evaluate the operation reliability of microgrids. It is a relatively complete reliability assessment, but it 
does not specify the effect of environmental conditions on reliability. In reference [16], the microgrid operational reliability is calculated by discussing the quantitative effect of protection system. However, it still not takes environmental conditions into consideration.

As more and more power electronics function as the interface of renewable energy integration in microgrids, the reliability performance of power electronics plays an important role in microgrid reliability. In recent years, there have been research on power electronics reliability. Literature [17] provides a review of reliability evaluation of power electronics, and

reference [18] shows the extensive application of FIDES model in reliability assessment of power electronic devices. Power electronics technology provides a compact and efficient solution for power conversion, based on that, the reliability of the small wind power converter system is evaluated in reference [19]. But the paper considers the relationship between power loss and power electronics failure rates without considering the impact of the system's operating states. The power electronics reliability in reference [20]-[25] are evaluated by taking mission profile into consideration. However, the effect of power electronic devices on microgrid reliability evaluation was still not discussed much in previous research.

\subsection{Reliability Evaluation model of power electronic systems}

Reliability evaluation plays a crucial role in design and operation management of the systems. Quantitative reliability evaluation of power electronic converters is necessary to determine whether a particular design conforms to certain specifications [26]. All the models involved in reliability analysis can be divided into two categories, which are at the component level or at the system or subsystem level. 


\subsubsection{Component-Level Reliability Models}

Component level is mainly for power electronic devices, such as power semiconductors, capacitors, and magnetic devices [27-32]. Field experiences proves that electrolytic capacitors and power switches, such as IGBTs and MOSFETs, are the most vulnerable components in power circuits illustrated in reference [26].

Components reliability is analyzed by quantifying model variables based on empirical data or failure physical analysis and calculating the corresponding reliability indices. The major premise is that effective failure rate data can be easily obtained from field application or laboratory test.

There are many empirical-based reliability models of electronic devices, but the military manuals for the reliability prediction of electronic devices (Military-manuals-217) are well known and widely accepted in both military and industrial applications[33]. However, the reliability manual has some limitations[34]. One limitation is that the model in MIL-217 assumes the failure rate of components is unchanged during its lifetime[35]. Constant failure rate is a long-time average value. However, the average failure rates cannot represent the components' failure probability under different operating and environment conditions. Another major limitation is that the reliability results from these models are usually higher and lead to expensive conservative designs.

Moreover, the failure rate models of some commonly used components such as IGBT is not mentioned in the manual. Instead, the reference values of MOSFET are often chosen to analyze the failure rate of IGBT.

\subsubsection{System or Subsystem-Level Reliability Models for micro-grid Systems}

The system-level reliability analysis is aimed at a device or working system consist of a 
large number of devices. Several methodologies to quantify the reliability metrics of power electronic converters have been introduced.

\section{A. Reliability Block Diagram (RBD) Method}

RBD represents the components or subsystems in block diagram form by considering the function of each component or subsystem. It's a kind of statistic model for it simplifies the reliability modeling process because the order of fault occurrence does not affect the model and result[3]. Therefore, RBDs are suitable for systems where the order of the failures does not matter.

It is not difficult to construct, revise, and verify the RBDs based on the integration of the system. In total, there are three kinds of structures: series structures, parallel structures and k-out-of-n structures in RBDs.

A series connection is formed by one path from the "in" node to the "out" node while a parallel connection is formed by multiple paths, and $\mathrm{k}-\mathrm{out}-\mathrm{of}-\mathrm{n}$ is functioning if at least $\mathrm{k}$ of $\mathrm{n}$ components are functioning or healthy. Figure 1-5 shows an RBD example of a simple system with three components (A, B, and C), and multiple paths from the "in" point to the "out" point.

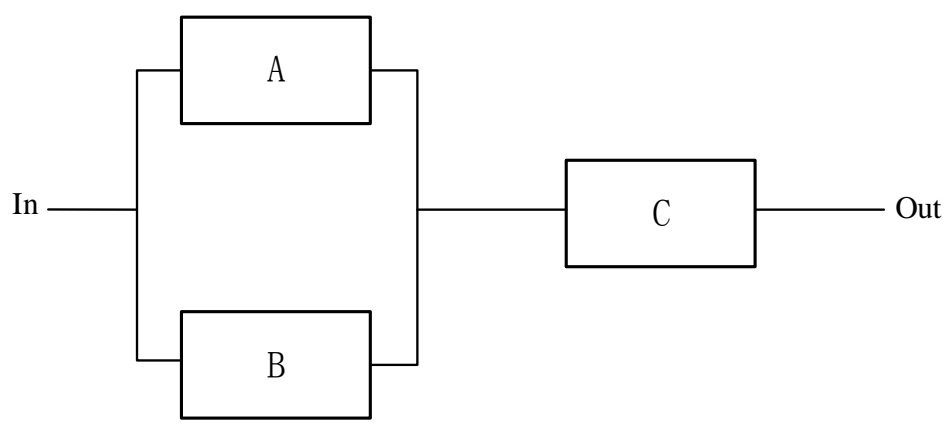

Figure 1-5 A simple RBD example[3] 
In Figure 1-5, if $\lambda_{l}$ is the failure rate of " $A$ ", $\lambda_{2}$ is the failure rate of "B", and $\lambda_{3}$ is the failure rate of "C", $R(t)$ and MTTF of the diagram in Figure 1-5 become formulas (1.1) and (1.2). In this paper, all the failure distributions are assumed to have exponential distributions.

$$
\begin{gathered}
R(t)=e^{-\left(\lambda_{1}+\lambda_{3}\right) t}+e^{-\left(\lambda_{2}+\lambda_{3}\right) t}-e^{-\left(\lambda_{1}+\lambda_{2}+\lambda_{3}\right) t} \\
\operatorname{MTTF} \frac{1}{\lambda_{1}+\lambda_{3}}+\frac{1}{\lambda_{2}+\lambda_{3}} \frac{1}{\lambda_{1}+\lambda_{2}+}
\end{gathered}
$$

\section{B. Fault tree analysis method}

Fault tree analysis model is a reliability model that represents the logical relationship between system failure and component failure through tree structure. Fault tree models usually consist of top events, intermediate events and basic events. Through the tree model, we can find out all the bottom events that cause the top event as far as possible. The fault tree analysis model is composed of events and logic gates. Therefore, FTA can be used for qualitative analysis and quantitative calculation. Figure 1-6 shows the fault tree with "AND" gates, "OR" gates, and events of the diagram in Figure 1-5. "OR" gate indicates that any occurrence of any failure in the lower layer will result in the occurrence of the top event, and the "AND" gate indicates that the top event will not occur until all events at the lower level occur simultaneously. A and B are the basic events, and the top event is represented by the letter T. The probability of the occurrence of a top event can be expressed as:

$$
P(T)=P(|A| \quad \text { i }
$$

The probability of calculating the fault tree analysis model is equivalent to the failure rate in the reliability indices, and the subsequent quantitative evaluation method is consistent with the 
RBD method, and the reliability and MTTF are obtained through the reliability indices calculation formula.

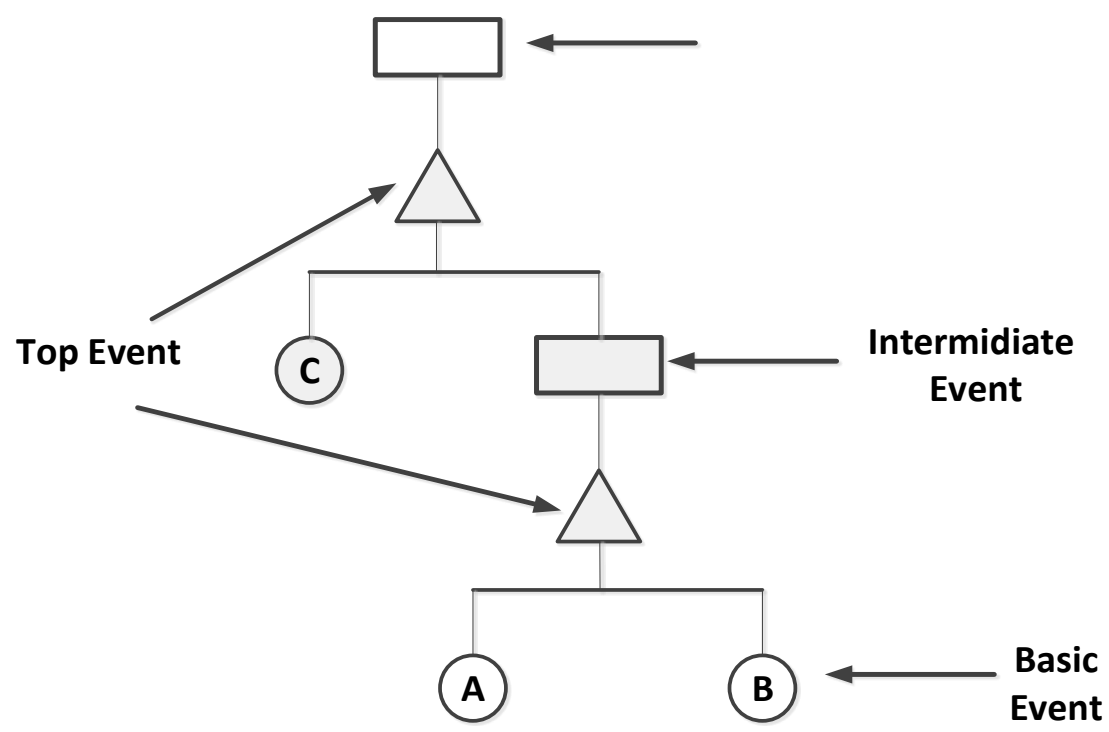

Figure 1-6 A simple fault tree diagram example [3]

Fault tree analysis model can directly express the logical relationship between system fault and component fault, and calculate the fault probability of the system as well. The fault tree analysis model has the advantages of clear structure and simple solution, but it is a static model which means it does not have the ability to analysis system with fault running state. The scope of application is limited.

The RBD and FTA are both used as the static reliability analysis model. They two modeling principles are similar to each other. The transformation can be easily got between them two and the results of quantitative calculation are basically consistent. They both own the advantages of fast modeling, clear structure, intuitive model and simple calculation, but are unable to express the defects of the system with fault operation ability, so the scope of application of them are basically the same. 


\section{Short-term outage model}

A short-term outage model is used to calculate system short-term reliability indices in microgrids. Three short-term reliability indices in microgrid system are defined as same as the ones applied for distribution system, namely system average interruption frequency index (SAIFI), system average interruption duration index (SAIDI), and energy not supplied index (ENS) [16]

Their corresponding expressions can be described as follows:

$$
\begin{aligned}
& \text { SAIFI }=\frac{\sum_{i=1}^{N} \lambda_{L P, i} m_{i}}{\sum_{i=1}^{N} m_{i}} \\
& \text { SAIDI }=\frac{\sum_{i=1}^{N} U_{i} m_{i}}{\sum_{i=1}^{N} m_{i}} \\
& \text { ENS }=\frac{\Delta t \sum_{i=1}^{N} L_{i}}{\sum_{i=1}^{N} m_{i}}
\end{aligned}
$$

in above formulas, $\lambda_{L P, i}$ is the failure rate for load point $\mathrm{i}, U_{i}$ is the outage time for load point $\mathrm{i}$. $m_{i}$ is the number of customers that the $i$-th load point supplies, $\Delta t$ is the time interval to calculate the reliability of the real time operation and $L_{i}$ is the load not supplied at $i$-th load point.

A short-term outage model can calculate the system average short-term outage time, average failure rate and the outage time for each load. It establishes correspondence between the failure rate of each micro-source with the outage time of each load point by system repair time matrix.

$$
\left[\begin{array}{c}
U_{1} \\
U_{2} \\
\vdots \\
U_{N}
\end{array}\right]=\left[\begin{array}{cccc}
r_{11} & r_{12} & \cdots & r_{1 M} \\
r_{21} & r_{22} & \cdots & r_{2 M} \\
\vdots & \vdots & \cdots & \vdots \\
r_{N 1} & r_{N 2} & \cdots & r_{N M}
\end{array}\right] \cdot\left[\begin{array}{c}
\lambda_{1} \\
\lambda_{2} \\
\vdots \\
\lambda_{M}
\end{array}\right]
$$




$$
\begin{gathered}
h(i, j)= \begin{cases}0, & r_{i j}=0 \\
1, & r_{i j}>0\end{cases} \\
\lambda_{L P, i}=h(i,:) \cdot\left[\begin{array}{c}
\lambda_{1} \\
\lambda_{2} \\
\vdots \\
\lambda_{M}
\end{array}\right], \quad i=1,2, \cdots, N \\
r_{L P, i}=\frac{U_{i}}{\lambda_{L P, i}}, \quad i=1,2, \cdots, N
\end{gathered}
$$

where $\lambda_{1}, \lambda_{2}, \cdots, \lambda_{M}$ are the failure rate of each micro-source which include both the failure rate of the power electronics and the micro-source itself, $r$ matrix is the repair time, and $r_{L P}$ is the repair time at load point i.

\subsection{Research Objective and Thesis Layout}

The main goal of this thesis first is to calculate power electronic devices' real-time failure rate according to their operational states and environmental situation. And then evaluate the microgrid system reliability by considering the real-time failure rates of power electronics. A converter's real-time failure model in wind turbine, solar system and energy storage system will be built. For wind turbine converter real-time failure model, the effect of wind speeds operating condition and ambient temperature is considered. For PV converter real-time failure model, the effect of illumination as well as ambient temperature is taken into consideration. For energy storage system's converter real-time failure model, the input and output power at the terminal of it are the crucial needed to be modified in the model. A case study is carried out, and microgrid reliability indices considering power electronics is evaluated under different situation, illustrate the performance of the proposed model and assessment approach. Then, the simulation results are analyzed and some conclusion have been made. Finally, sensitivities analyses are made to 
compare the real-time indices to constant indices, and other influences.

The paper is organized as following. Chapter 2 provides the model for calculating the failure rates of power electronic devices considering the different operational states; Chapter 3 presents the model for microgrid reliability evaluation considering power electronic devices based on a case study, also make a contrast under different situation and a conclusion is drawn. And the sensitivities analysis is proposed in chapter 4; The conclusions are presented and future work is prospected in chapter 5 . 


\section{Chapter 2 Failure Rates of Power Electronics}

\subsection{Introduction}

In reliability evaluation, two types of models are commonly used to evaluate the power electronics failure rate. One is empirical-based reliability model which largely based on historical data, another is physics-of-failure model. The current running microgrid system does not have enough data to support the former one and it has the limitation of treating the failure rate as a constant value. And the second one is more suitable for it can obtain reliability of power electronics under different operational conditions by considering the different environmental statements.

References [24] and [25] studies the effects of wind speed and tidal current velocity on the reliability of power electronics. However, in previous researches, the assessment of power electronic failure rates from the perspective of the microgrid system, taking into account the different types of renewable generation and energy storage in the system has not been carried out.

In this study, the failure rates of the power electronic interfaces for solar and wind generators and energy storages are evaluated, considering the real power flow from the system perspective, as well as the influences of different meteorological conditions, like ambient temperature, illumination and wind speed, at the same time.

\subsection{Model Establishment}

In this model, a converter real-time failure rate model considering the effect of meteorological conditions is built. The reason is the output power is affected by varied 
meteorological conditions and different output power of the renewable generators and charging rate of energy storages causes different power loss on power electronic components, leading to different temperature rise and finally causing the components fail.

The logic diagram of this model is shown below.

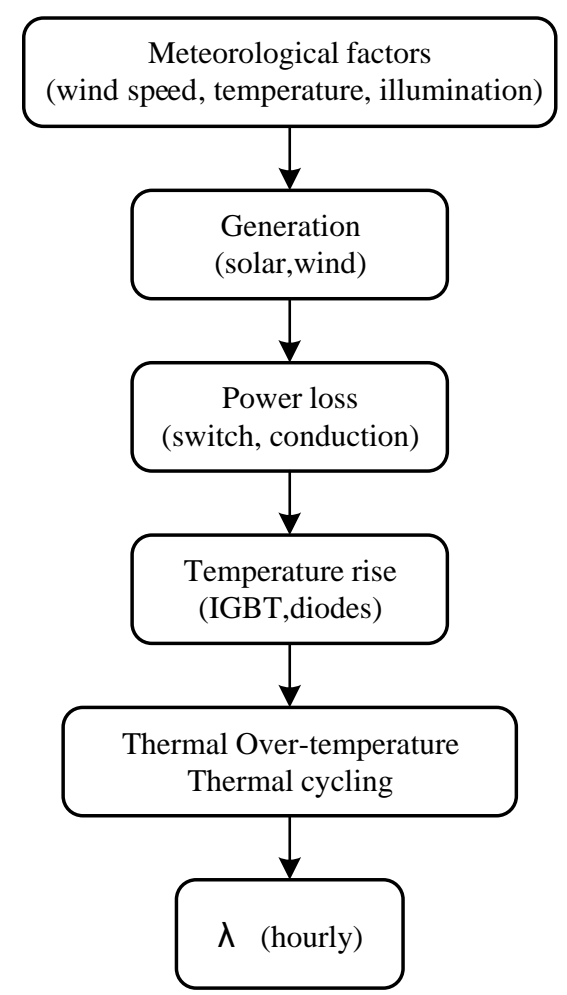

Figure 2-1 Real-time converter outage model

As shown in Figure 2-1, if we input the hourly meteorological data (ambient temperature, illumination and wind speed) into this model we can calculate the real-time failure rate.

\subsubsection{Output Power of Renewable Energy Resources}

A. Wind turbine generators 
The output power of WTG varies with the random variation of wind speed. First the relationship between the wind speed and windfarm output is expressed as [36]

$$
P_{w}=\left\{\begin{array}{cc}
P_{w r}, & v_{r} \leq v<v_{c o} \\
P_{w r} \cdot \frac{v-v_{c i}}{v_{r}-v_{c i}}, & v_{c i} \leq v<v_{r} \\
0, & \text { otherwise }
\end{array}\right.
$$

As shown above $P_{w}$ is the power output of the wind turbine, $P_{w r}$ is the wind turbine rated output, $v$ is the wind speed, $v_{c i}$ and $v_{c o}$ are the cut-in and cut-out wind speed. It is not difficult to find that when the wind speed exceeds the rated wind speed, the output power remains constant. When the wind speed is below cut-in speed or exceeds cut-out speeds, the wind turbine stops working.

\section{B. photovoltaic arrays}

For photovoltaic arrays, the output power is mainly affected by illumination and ambient temperature. According to reference [15], the output power can be calculated as below:

$$
P_{s}=P_{s r}\left[1-0.0045\left(T-T_{r}\right)\right] \frac{I}{I_{r}}
$$

as shown above $P_{S}$ is output power of the photovoltaic array, $P_{s r}$ is the rated output of the photovoltaic array, $T$ is the ambient temperature, $I$ is the illumination, $T_{r}$ is the reference temperature and $I_{r}$ is the reference illumination.

C. Charging Control for the Energy Storage 
In this study, the microgrid is operated in islanded mode, means that loads are supplied by either the renewable energy sources or energy storage. The load point is restored in accordance with its electrical distance with the micro source, and the algorithm in [15] is adopted. If the total capacity is larger than the total load demands in the system, then the energy storage will be charged. Assuming that the energy storage is large enough to store all remaining capacity.

Therefore, the input and output power of the energy storage terminal $\left(P_{e}\right)$ can be expressed as:

$$
P_{e}=\sum_{i=1}^{N} P_{i}-\sum_{j=1}^{M} L_{j}
$$

as shown above, $P_{i}$ is the output power of the $i$-th micro-source, $N$ is the number of microsources, $L_{j}$ is the load at the $j$-th load point and $M$ is number of load points.

\subsubsection{Calculating the Power Loss of Converter}

As said in chapter 1, the voltage source converters(VSC) used in this paper includes 6 diodes and 6 IGBTs. According to the operating characteristics of the VSC, the power loss of the VSC is the power loss of each diode and IGBT in the VSC[Effect of Wind Speed on Wind Turbine Power Converter Reliability]. The loss on each diode and IGBT can be expressed as follows[37][39]:

$$
\begin{aligned}
& P(\text { diode })=V_{\text {diode }} I\left(\frac{1}{2 \pi} \mp \frac{M}{8} \cos \theta\right)+R_{\text {diode }} I^{2}\left(\frac{1}{8} \mp \frac{M}{3 \pi} \cos \theta\right)+\frac{f}{\pi} \cdot \frac{V_{D C^{I}}}{V_{\text {ref,diode } I_{\text {ref, diode }}}} E_{\text {diode }} \\
& P(I G B T)=V_{I G B T} I\left(\frac{1}{2 \pi} \pm \frac{M}{8} \cos \theta\right)+R_{I G B T} I^{2}\left(\frac{1}{8} \pm \frac{M}{3 \pi} \cos \theta\right)+\frac{f}{\pi} \cdot \frac{V_{D C I}}{V_{\text {ref,IGBT } I_{\text {ref }, I G B T}} E_{\text {on }}+E_{\text {off }}}
\end{aligned}
$$


in which $V_{\text {diode }}$ and $V_{I G B T}$ are the voltage drops across the diode and IGBT; $R_{\text {diode }}$ and $R_{I G B T}$ are the conduction resistance of the diode and IGBT respectively; $E_{\text {diode }}$ is the rated switching loss on the diode, $E_{\text {on }}$ and $E_{\text {off }}$ are the power losses of IGBT during the operation; $V_{D C}$ is DC link voltage; $V_{\text {ref,diode }}$ and $V_{\text {ref,IGBT }}$ are the reference commutation voltage of diode and IGBT; $I_{\text {ref,diode }}$ and $I_{\text {ref,IGBT }}$ are the reference commutation current of diode and IGBT; $M$ is the modulation index and $\theta$ is the angle between the voltage and current.

In formula (2.4) and (2.5), I is the peak value of phase current, which can be approximately calculated by [37]

$$
I \approx \frac{\sqrt{2} P}{\sqrt{3} U}
$$

In which $\mathrm{P}$ is the output power of the micro-sources and $\mathrm{U}$ is the line-to-line voltage on generation side or grid side.

Based on the power loss on each IGBT and diode, the total power losses of the converter can be calculated by:

$$
P_{\text {loss }}=\sum_{i=1}^{N 1} P_{I G B T, i}+\sum_{j=1}^{N 2} P_{\text {diode }, j}
$$

in which $N 1$ is the number of IGBTs involved in the converter and $N 2$ is the number of diodes included in the converter. Then, the temperature rise in the converter can be calculated as below [37]:

$$
T_{\text {module }}=T_{\text {ambient }}+R_{\text {ha }} P_{\text {loss }}
$$


where ambient temperature is expressed by $T_{\text {ambient }}$ and thermal resistance from the heatsink of the power electronic module to the ambient is expressed by $R_{h a}$.

\subsubsection{Calculating Failure Rates of Power Electronic Modules}

Literature [19] illustrates that power electronic failures are mainly determined by two main factors: thermal over-temperature and thermal cycling and it is evaluated with different phases considered in a long-term. In my paper, I also consider the effect of these two factors on the failure of converters.

But in this study, with the application of short-term model, the failure rate in each hour is evaluated that only includes a single phase of operation. Therefore, the failure rate of power electronics can be calculated shown as [18]:

$$
\lambda=\prod_{P M} \prod_{\text {process }} \prod_{\text {induced }}\left(\gamma_{T H} \prod T H+\gamma_{T C} \prod T C+\gamma_{M} \prod M+\gamma_{R H} \prod R H\right)
$$

where $\Pi_{P M}$ is manufacturing factor reflecting the quality of the component, $\Pi_{\text {process }}$ is the factor that reflects the aging quality of the component during its life cycle, $\Pi_{\text {induced }}$ is the factor reflecting its overstress ability, $\lambda_{M-R H}$ and $\lambda_{T H-T C}$ are basic failure rates influenced by mechanical/humidity and factors temperature/thermal cycling, respectively, and $\gamma_{T H}, \gamma_{T C}, \gamma_{M}$, $\gamma_{R H}$ are the basic failure rates related to temperature (temperature, thermal cycling, mechanical factor and humidity).

Here, $\Pi_{T H}$ and $\Pi_{T C}$ are the thermal factor and thermal cycling factors which related to temperature rise, respectively, and they can be expressed as follow: 


$$
\begin{gathered}
\Pi_{T H}=\exp \left(11604 \times 0.44 \times\left[\frac{1}{293}-\frac{1}{T_{\text {ambient }}+\Delta T+273}\right]\right) \\
\Pi_{T C}=12 \times \sqrt[3]{0.5} \times\left(\frac{\Delta T_{\text {cycling }}}{20}\right)^{2.5} \times \exp \left(1414 \times\left[\frac{1}{313}-\frac{1}{T_{\text {max }+273}}\right]\right)
\end{gathered}
$$

in which $\Delta T=10^{\circ} \mathrm{C}, \Delta T_{\text {cycling }}$ is the temperature variation in a phase and $T_{\max }$ is the maximum temperature in a phase. Other details can be found in [18].

\subsection{Model test}

After building the real-time failure model, next step is to test the model to see if the model is working well before putting the model into use. The main parameters for this model are shown in below Table:

\begin{tabular}{cc|cc}
\hline parameters & values & parameters & values \\
\hline$V_{I G B T}$ & $1.54 \mathrm{~V}$ & $E_{\text {diode }}$ & $0.39 \mathrm{~J}$ \\
$R_{I G B T}$ & $0.84 \times 10^{-3} \Omega$ & $U$ & $690 \mathrm{~V}$ \\
$f$ & $3000 \mathrm{~Hz}$ & $N_{1}$ & 6 \\
$E_{\text {on }}$ & $0.50 \mathrm{~J}$ & $N_{2}$ & 6 \\
$E_{\text {off }}$ & $0.57 \mathrm{~J}$ & $R_{\text {ha }}$ & $0.454^{\circ} \mathrm{C} / \mathrm{W}$ \\
$V_{D C}$ & $1100 \mathrm{~V}$ & $\Pi_{P M}$ & 0.16 \\
$V_{\text {ref,IGBT }}$ & $1700 \mathrm{~V}$ & $\Pi_{\text {process }}$ & 0.4 \\
$I_{\text {ref,IGBT }}$ & $2400 \mathrm{~A}$ & $\Pi_{\text {induced }}$ & 7.12 \\
$U_{g}$ & $563.4 \mathrm{~V}$ & $\gamma_{T H}$ & 0.359 \\
$V_{L L}$ & $690 \mathrm{~V}$ & $\gamma_{T C}$ & 0.523 \\
$V_{\text {diode }}$ & $0.81 \mathrm{~V}$ & $\gamma_{M}$ & 0.9 \\
$R_{\text {diode }}$ & $1.5 \Omega$ & $\gamma_{R H}$ & 0.028 \\
\hline
\end{tabular}

Table 2-1 Main parameters of the converter real-time failure model

First, the real 24-hour temperature and wind speed in summer in Milwaukee is used to test the accuracy of this model, and they are shown below: 

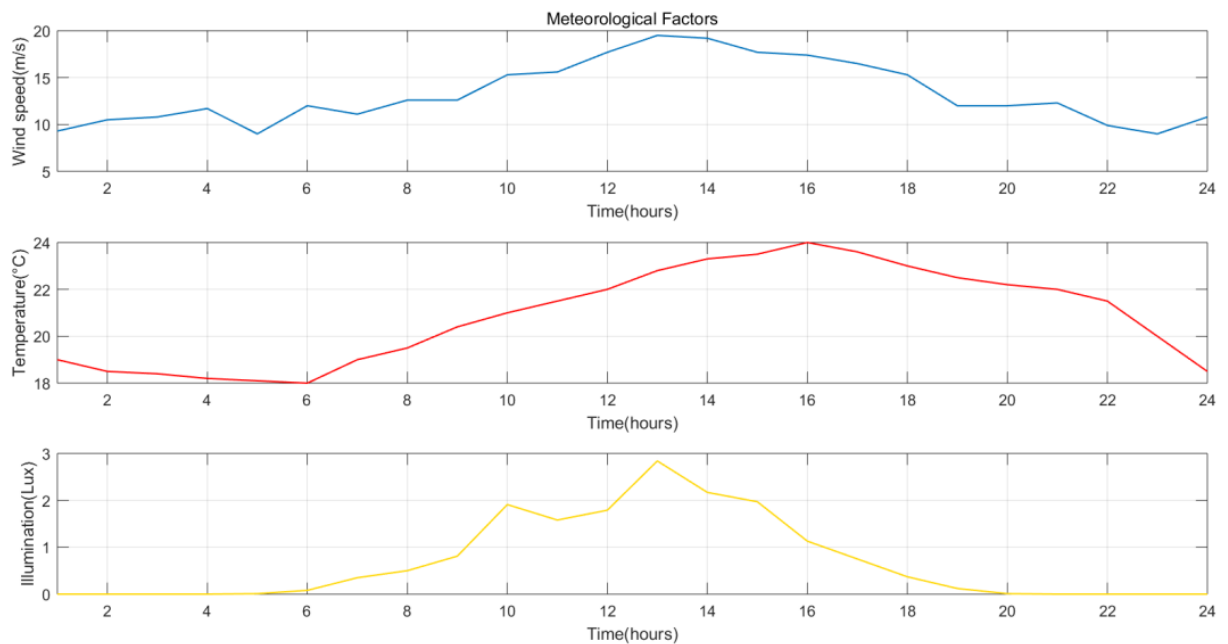

Figure 2-2 Meteorological conditions during the day in summer Milwaukee

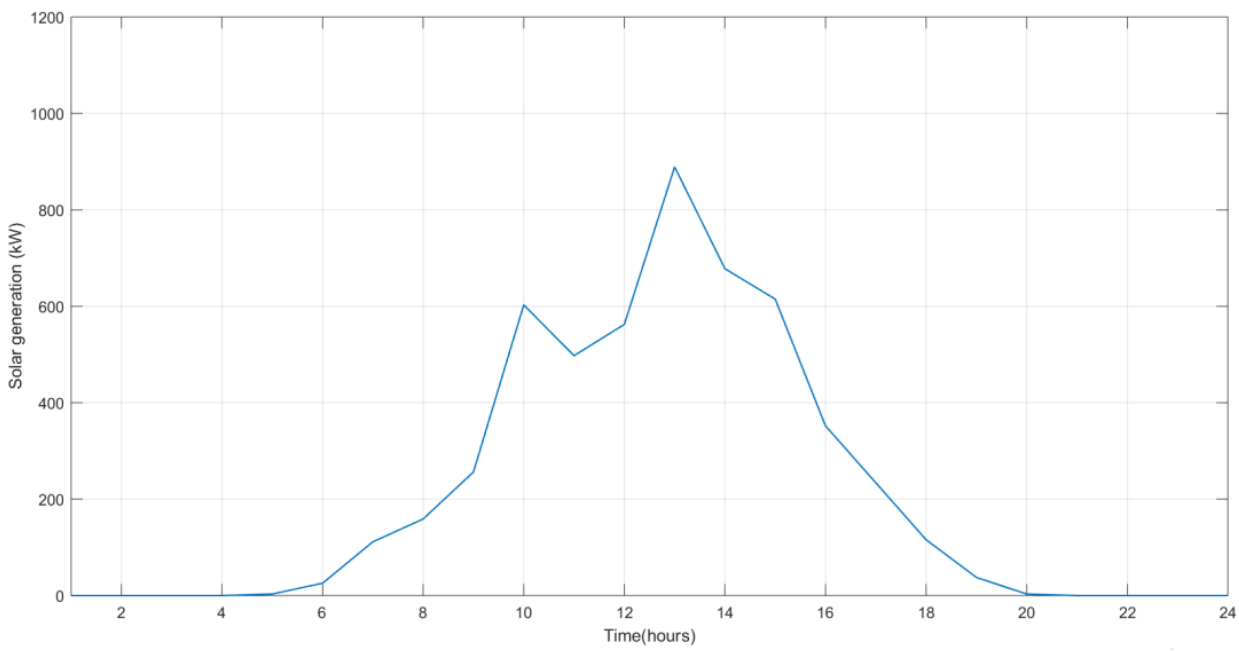

Figure 2-3 Real-time PV power output

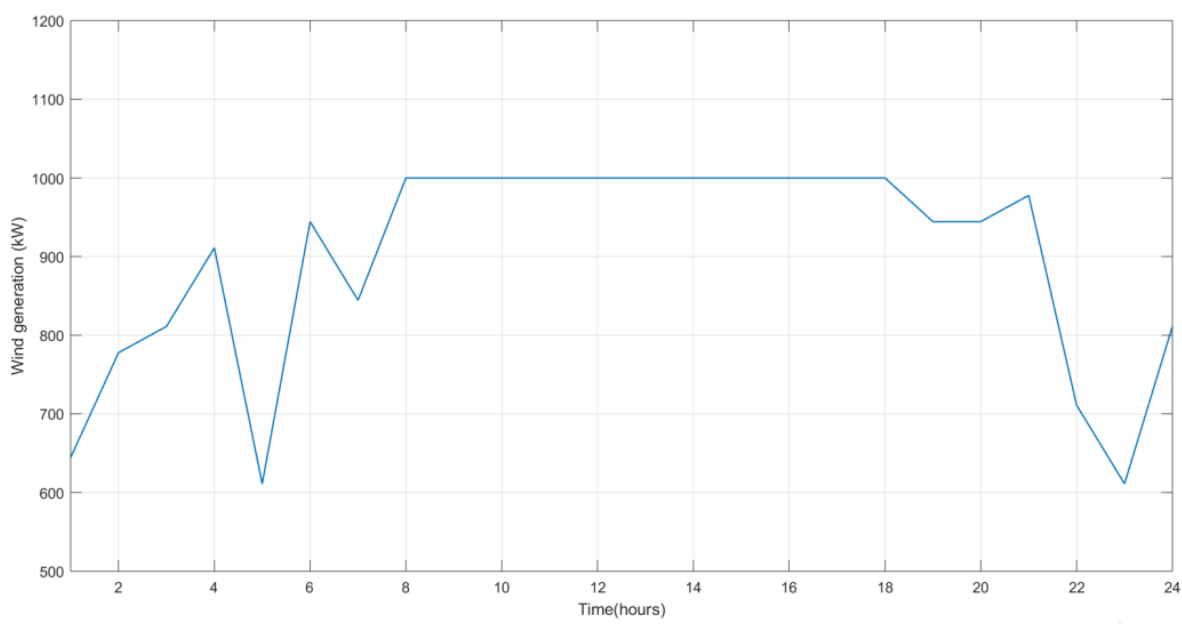

Figure 2-4 Real-time wind power output 
As we can see from Figure 2-3, between 8:00 to 19:00, the PV power output reaches its highest point at13:00 for the illumination gets its highest point at that time. And before 5:00 and after 20:00, the output power of solar keeps zero as the illumination are zero during this period. As we can see from Figure 2-4 between 8:00 to 19:00, the wind power output remains 1000KW, because the wind speed reaches the rated speed.

Based on the real-time data, the operating failure rate for wind turbine can be calculated below:

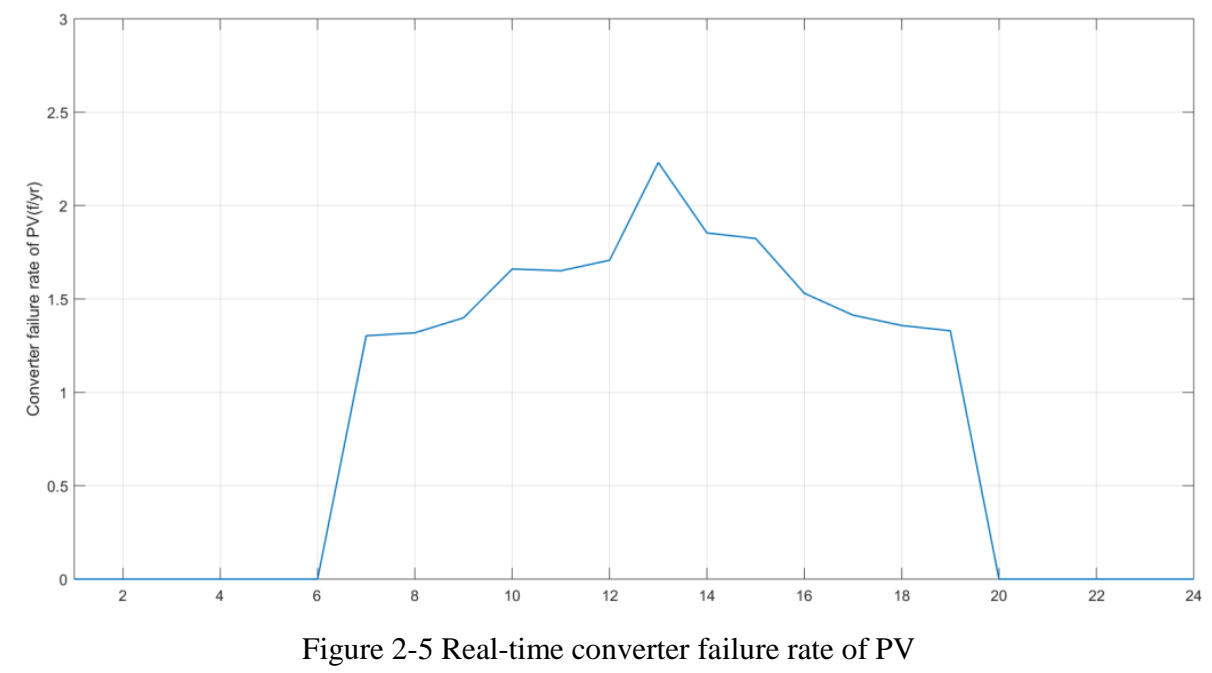

As shown above, the failure rate reached a minimum of 0 failure per year before 5:00 and after 20:00 and reached the highest point 2.20 at 13:00. 


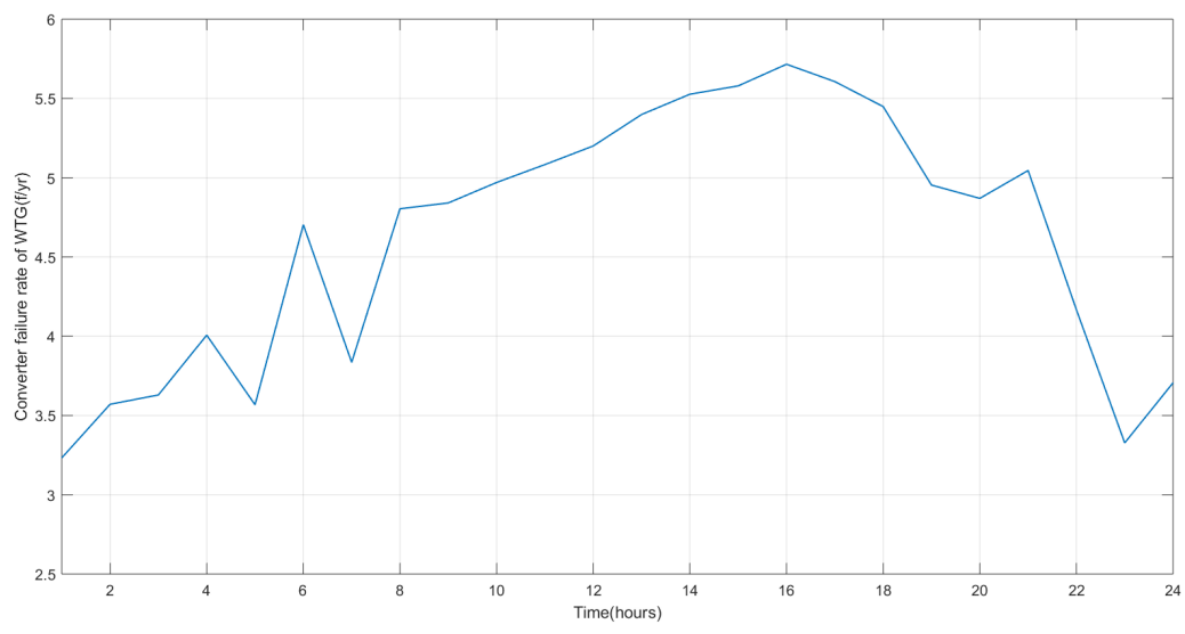

Figure 2-6 Real-time converter failure rate of wind turbine

As shown above, the failure rate of wind turbine reached a minimum of 3.25 failure per year at 1:00 and reached the highest point 5.70 at 16:00.

In order to see the effect of operating environment specifically, we show the wind turbine generator failure rate curve in comparison with the meteorological conditions:
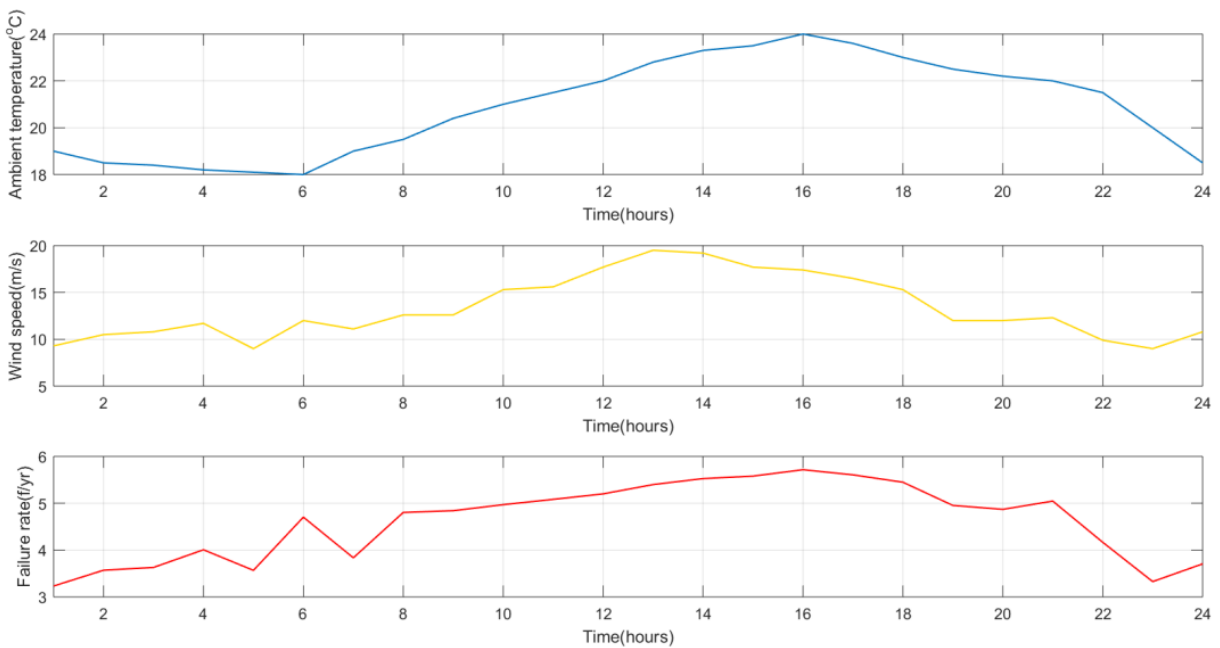

Figure 2-7 The failure rate of wind converter and its influence factors

From the curves above we can find that, before 8:00, the failure rate curve has the same pattern with wind speed while after 8:00, the failure rate curve is very similar to the ambient temperature curve. We can find the reason from the model, the temperature rise which causes the 
failure consists of two parts, one is ambient temperature, another is power losses which is the function of wind speed. In normal situation which the coefficient of power losses is larger than that of ambient temperature, as a result, the wind speed affects the failure rate more than the ambient temperature. However, after 8:00, when the wind speed exceeds the rated wind speed $V_{r}$, the output power remains constant at the rated output, making the power losses of wind turbine remains constant and didn't affect the temperature rise any more.
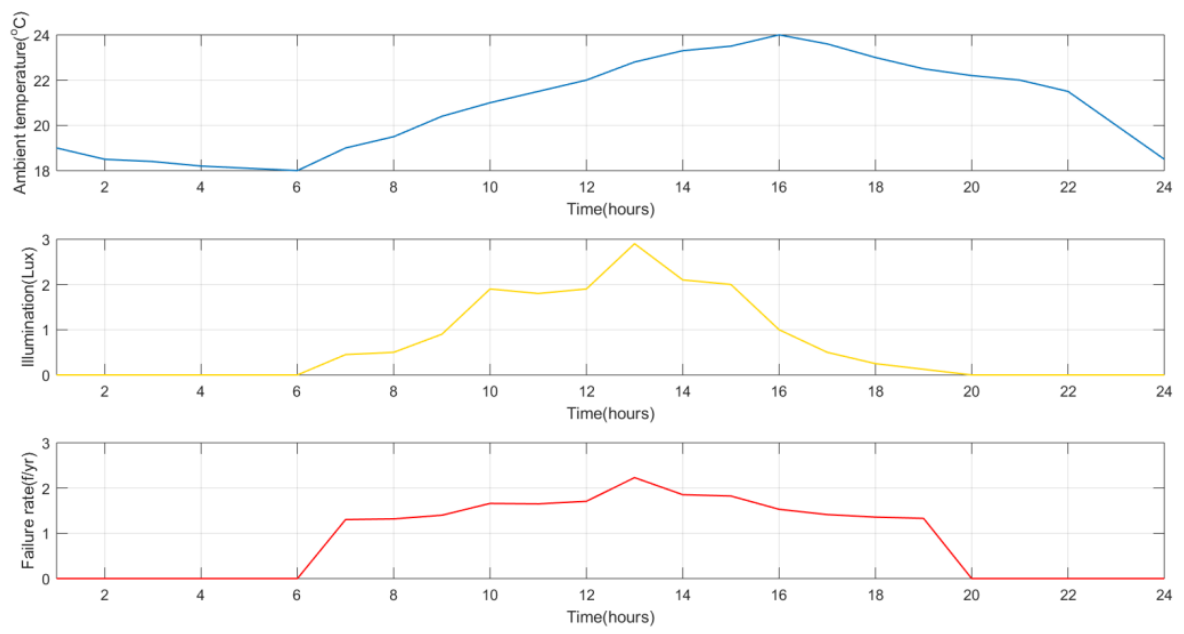

Figure 2- 8 The failure rate of PV converter and its influence factors

The failure rate reaches its highest point as the illumination reaches its peak at 13:00, and it is not difficult to find that the real-time failure rate curve has the same pattern with the illumination curve, but is not exactly the same. Take the data at 6:00 and 7:00 as an example, the failure rate rises rapidly while the illumination rises slowly for the sake of the ambient temperature at 7:00 is larger than that at 6:00.

\subsection{Conclusion and Future work}

In this chapter real-time failure rate model for converters in micro-source are established and tested. For this model, first the hourly micro-source output is calculated from the real-time wind 
speed, illumination and ambient temperature. Then the total power losses of the power electronics are calculated and the temperature rise over the converter are got as well, where the temperature rise caused by the ambient temperature is also considered. Finally, the converter real-time failure rate can be calculated.

To test this model, the local meteorological data are used and be compared with the calculated failure rate. The result show that, with the real-time environmental conditions change, the converter failure rate will produce the corresponding change as well. For the converter of wind turbine, at the earlier time of a day, the effect of wind speed on the failure rate of the its converter is significant while at the later time of the day when the wind speed reaches its rated value, ambient temperature plays a more important role in the converter failure rate, as a result, the outage is more likely to happen during the daytime because of the high temperature. For PV converter, illumination is the most crucial part in the effect of converter failure and the outage will happen during the daytime because of the illumination.

In general, this model can better reflect the impact of operating environment and operating status on micro-sources failure rate.

Future work can be focused on the following aspects: considering the impact of extreme weather and its duration on converter failure rate; considering more weather conditions for the weather-dependent failure model; combining with climate forecast technology like wind speed, illumination and temperature to study the failure rate prediction of the converter. 


\section{Chapter 3 Case study}

\section{1 introduction}

In this chapter a 11-node network microgrid system are studied under Matlab environment. First, according to the physical system configuration and the parameters of each component in the system, the power flow is conducted under "Power World" environment. Next, by using the RBD method, topologies of the system are simplified to several sub-systems and their reliability index are calculated, respectively. Then, a short-term model was applied to calculate the reliability indices and some different cases are studied and the comparisons are made.

Before the case study, an indicator is illustrated which is called availability. For each component, the availability can be calculated from the expression below:

$$
A=\frac{M T T F}{M T T F+M T T R}
$$

In the formula above, $A$ is availability, MTTF represents mean time to failure and MTTR represents mean time to repair. Availability can also be calculated through failure rate $\lambda$ and repair rate $\mu$ :

$$
A=\frac{\mu}{\lambda+\mu}
$$

For the system or subsystem, the availability of energy is defined as the maximum energy that can be transmitted.

The remainder of this chapter is organized in the following way. The RBD Method to 
calculate availability for the case system is presented in section 3.3. The short-term model for the same case is adopted in section 3.4. The flow chart to evaluate the reliability of microgrid is shown below:

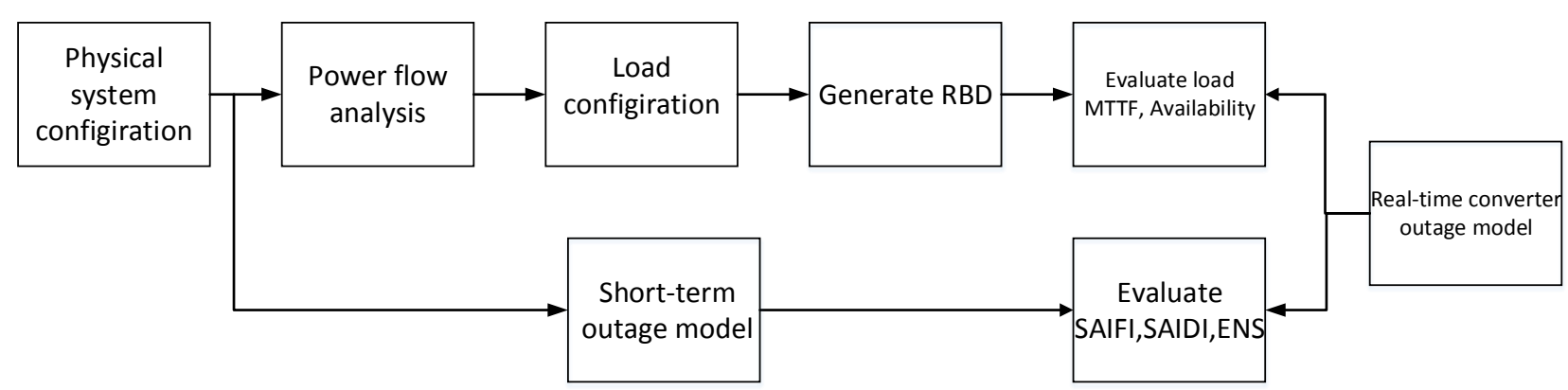

Figure 3-1 The flow chart to evaluate the reliability of Microgrid

\subsection{Test system}

a) Network: The network used in the case study has 11 nodes with 10 load points which are also illustrated in [15], Figure 3.2 shows the one-line diagram of the system, which has two tie lines, and feeder parameters are listed in Table 3-1.

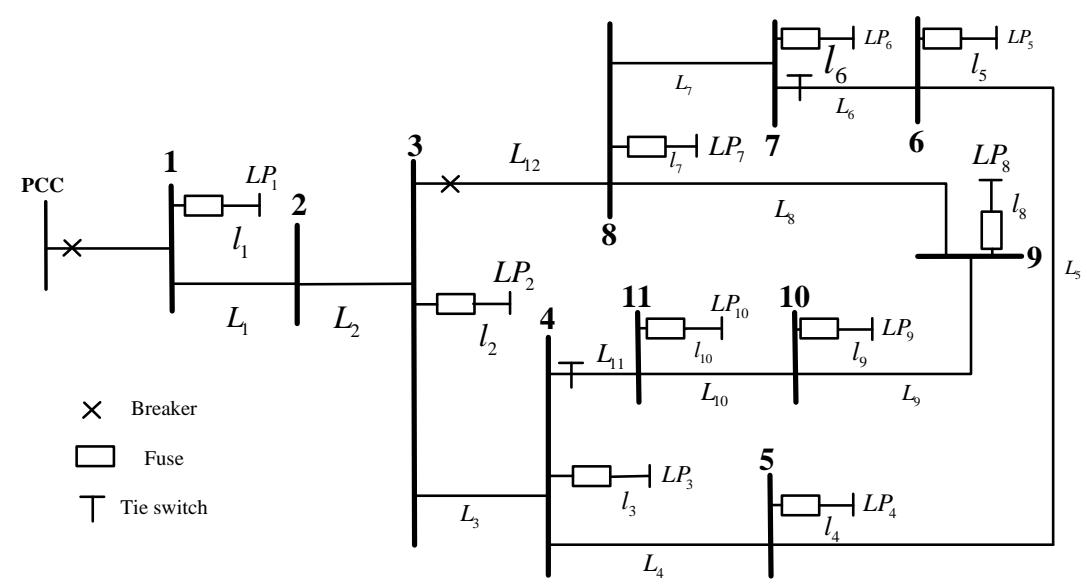

Figure 3-2 The microgrid network used in simulation

\begin{tabular}{ccccccc}
\hline No. & $R(\Omega \mathrm{km})$ & $X(\Omega / \mathrm{km})$ & $C(\mathrm{nF} / \mathrm{km})$ & $L(\mathrm{~km})$ & $I_{N}(\mathrm{~A})$ & $I_{S}(\mathrm{~A})$ \\
\hline
\end{tabular}




\begin{tabular}{ccccccc}
\hline$L_{1}$ & 0.579 & 0.367 & 9.93 & 0.282 & 100 & 125 \\
$L_{2}$ & 0.164 & 0.113 & 413 & 0.442 & 100 & 125 \\
$L_{3}$ & 0.262 & 0.121 & 405 & 0.061 & 50 & 63 \\
$L_{4}$ & 0.354 & 0.129 & 285 & 0.056 & 38 & 48 \\
$L_{5}$ & 0.336 & 0.126 & 343 & 0.154 & 38 & 48 \\
$L_{6}$ & 0.256 & 0.130 & 235 & 0.024 & 38 & 48 \\
$L_{7}$ & 0.294 & 0.123 & 350 & 0.167 & 38 & 48 \\
$L_{8}$ & 0.339 & 0.130 & 273 & 0.032 & 50 & 63 \\
$L_{9}$ & 0.399 & 0.133 & 302 & 0.077 & 38 & 48 \\
$L_{10}$ & 0.367 & 0.133 & 285 & 0.033 & 38 & 38 \\
$L_{11}$ & 0.423 & 0.134 & 310 & 0.049 & 38 & 48 \\
$L_{12}$ & 0.172 & 0.115 & 411 & 0.130 & 50 & 63 \\
\hline
\end{tabular}

Table 3-1 parameters of main feeder

b) Customer and load data: The load at each load point and parameters of the transmission lines are shown in Table 3-20 and is kept constant through 24 hours.

\begin{tabular}{|c|c|c|c|c|}
\hline \multirow[b]{2}{*}{ Node. NO. } & \multicolumn{2}{|c|}{ Residential } & \multicolumn{2}{|c|}{ Commercial } \\
\hline & $\begin{array}{c}\text { Load value } \\
\text { /kVA }\end{array}$ & $\begin{array}{l}\text { Number of } \\
\text { customers }\end{array}$ & $\begin{array}{c}\text { Load value } \\
\text { /kVA }\end{array}$ & $\begin{array}{l}\text { Number of } \\
\text { customers }\end{array}$ \\
\hline 1 & $7.50+\mathrm{j} \cdot 1.55$ & 50 & $2.50+\mathrm{j} \cdot 0.50$ & 2 \\
\hline 2 & - & - & - & - \\
\hline 3 & $2.76+\mathrm{j} \cdot 0.69$ & 50 & $2.24+\mathrm{j} \cdot 1.39$ & 2 \\
\hline 4 & $4.32+\mathrm{j} \cdot 1.08$ & 50 & - & - \\
\hline 5 & $7.25+\mathrm{j} \cdot 1.82$ & 50 & - & - \\
\hline 6 & $5.50+\mathrm{j} \cdot 1.38$ & 50 & - & - \\
\hline 7 & - & - & $0.77+\mathrm{j} \cdot 0.48$ & 2 \\
\hline 8 & $5.88+\mathrm{j} \cdot 1.47$ & 50 & - & - \\
\hline 9 & - & - & $5.74+\mathrm{j} \cdot 3.56$ & 2 \\
\hline 10 & $4.77+\mathrm{j} \cdot 1.20$ & 50 & $0.68+\mathrm{j} \cdot 0.42$ & 2 \\
\hline 11 & $3.31+\mathrm{j} \cdot 0.83$ & 50 & - & - \\
\hline
\end{tabular}

Table 3-2 Load parameters

c) The load curve of the microgrid system is produced by using the data in Table 3-1 as a reference value of the peak values. And I also make use of the load curve pattern in reference [44]. The load curves at all the load points of the system are shown in Figure 3-3. 


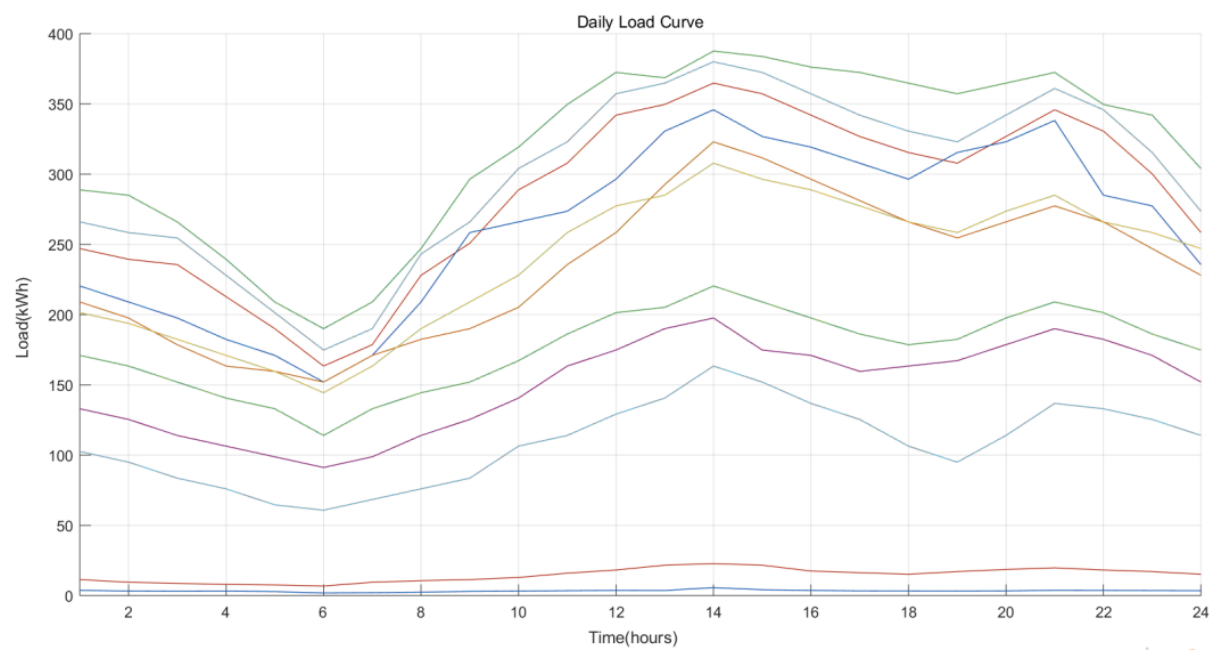

Figure 3-3 24-hour load curve in the network

d) Micro-sources: Three types of micro sources with total capacity of $19.65 \mathrm{MW}$ are deployed in the system, as described in Table 3-2. There are three PV arrays, one wind turbine generator and one energy storage, each with a power electronic interface and a breaker, in this network.

Because of the volatile and intermittent renewable generation, the power electronics failure rate varies all the time. Since this paper aims at studying how the changes of power electronics failure rate can affect the microgrid reliability, the failure rates of wind turbine, PV arrays and battery are selected according to references [45][46][47] and keep constant during the period we study, specifically, the failure rate of the wind turbine is chosen as $2.5 \mathrm{f} / \mathrm{yr}$, the failure rate of PV arrays $5 \mathrm{f} / \mathrm{yr}$, and the failure rate of the battery 2 f/yr. For breakers, the failure rate of breakers only includes that caused by malfunction so that it is chosen as $8 \mathrm{f} / \mathrm{yr}$ in reference [15], all the information of micro-sources are shown in Table 3-3.

\begin{tabular}{cccc}
\hline $\begin{array}{c}\text { Microsource } \\
\text { No. }\end{array}$ & Type of Microsource & $G_{\text {rate }} / k W$ & $\lambda(\mathrm{f} / \mathrm{yr})$ \\
\hline
\end{tabular}




\begin{tabular}{cccc}
\hline 3 & Photovoltaic & 7750 & 5 \\
5 & Photovoltaic & 3500 & 5 \\
6 & Wind turbine generator & 1000 & 2.5 \\
8 & Energy Storage & 800 & 2 \\
10 & Photovoltaic & 6600 & 5 \\
\hline
\end{tabular}

Table 3-3 Location, capacity and reliability data of micro sources

\subsection{RBD Method}

In this case, based on the parameters of the test network, first of all, the power flow for the system was acquired by using the software "Power World", which is given below:

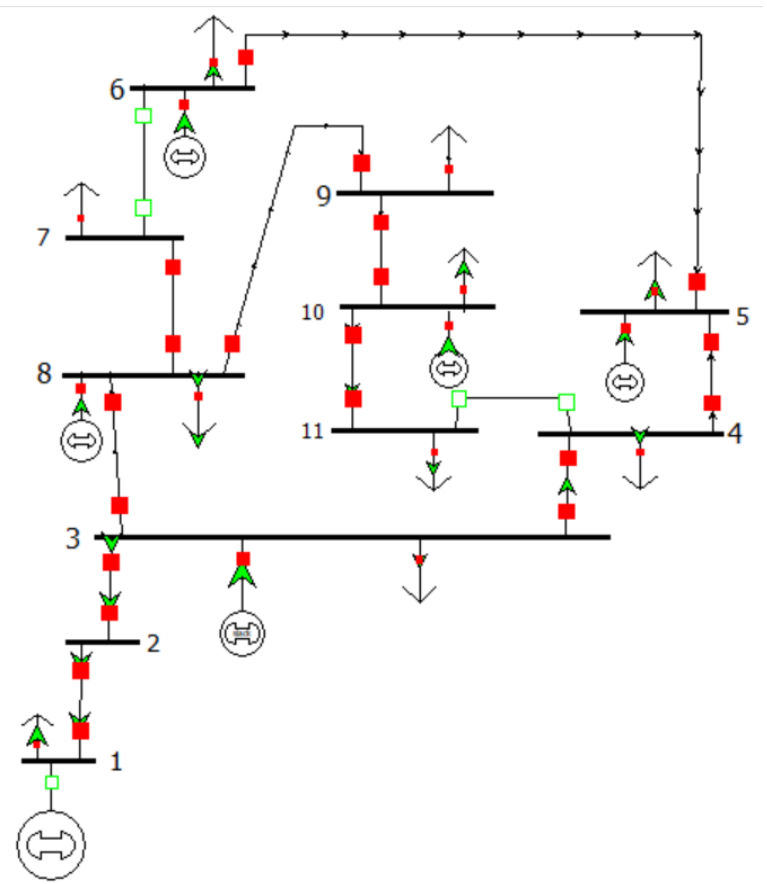

Figure 3-4 The network and its power flow

Combining with power flow analysis, we can draw load configuration for each load, according to different load configuration, this system can be simplified to five sub-systems and figure below. Here, $\lambda c 1, \lambda c 2, \lambda c 3, \lambda c 4, \lambda c 5$ are the failure rates of power electronic 
converters of three PV arrays, one wind turbine and one battery. $\lambda \mathrm{Br}$ is the failure rate of the breaker.

For subsystem 1 which includes load 1,3,4:

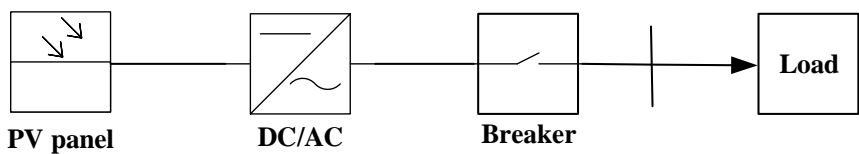

Figure 3-5 Micro-grid diagram for supporting load1,3,4

RBD of subsystem 1:

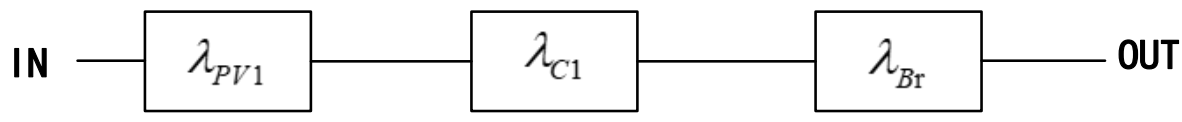

Figure 3-6 RBD of the micro-grid to support load1,3,4

For subsystem 2 which includes load 5:

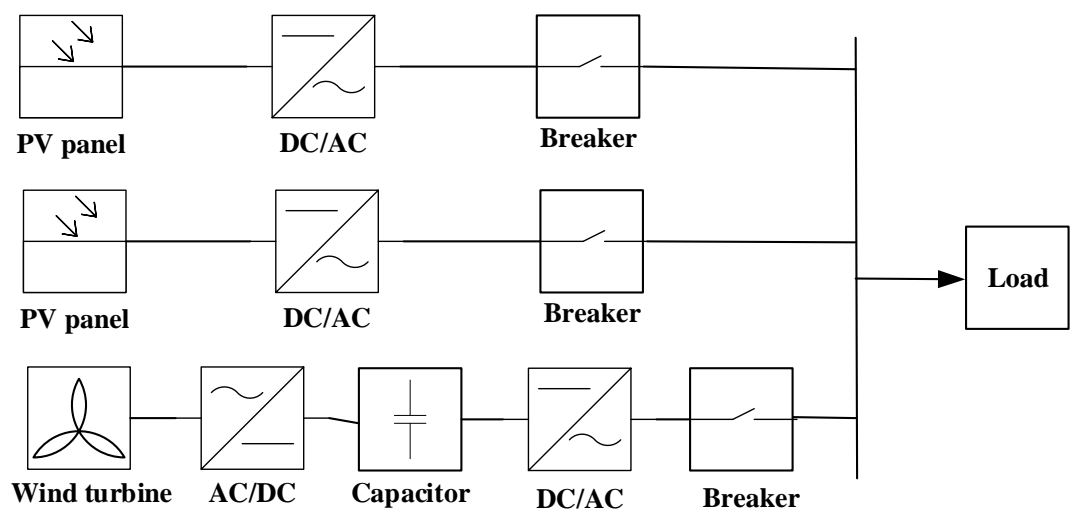

Figure 3-7 Micro-grid diagram for supporting load 5

RBD of subsystem 2: 


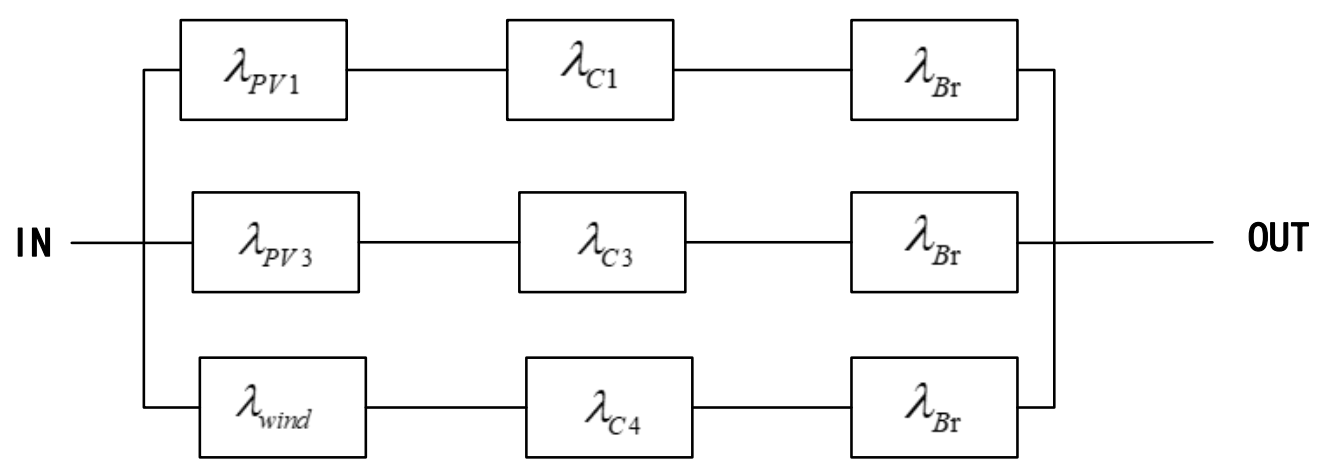

Figure 3-8 RBD of the micro-grid to support load 5

For subsystem 3 which includes load 6:

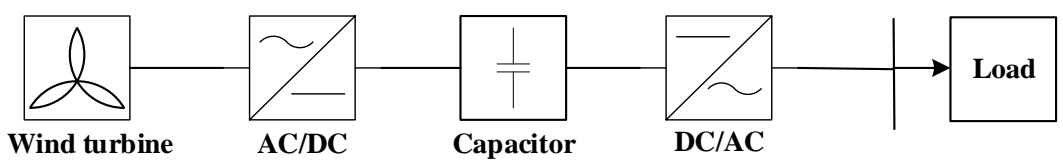

Figure 3-9 Micro-grid diagram for supporting load 6

RBD of subsystem 3:

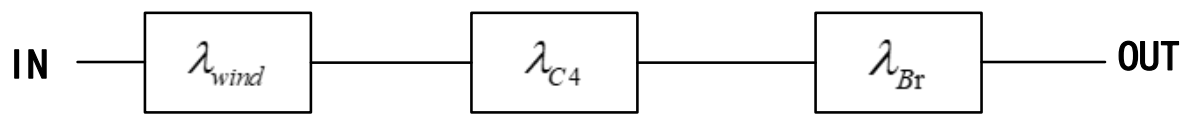

Figure 3-10 RBD of the micro-grid to support load 6

For subsystem 4 which includes load 7,8,9:

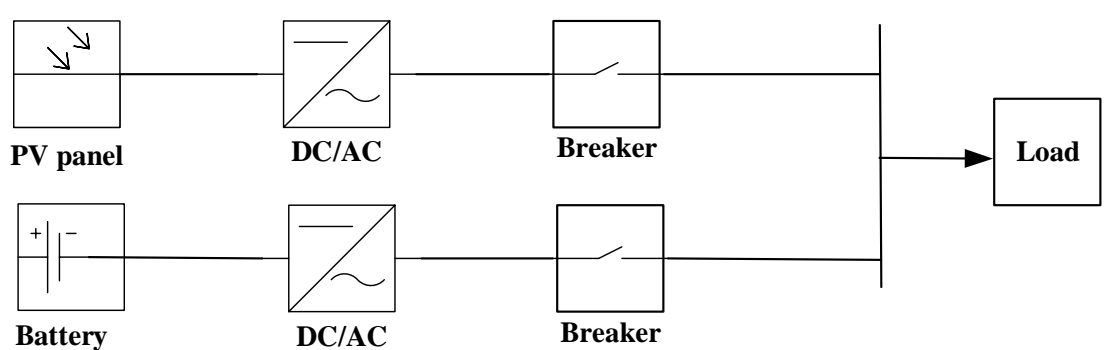

Figure 3-11 Micro-grid diagram for supporting load 7,8,9

RBD of subsystem 4: 


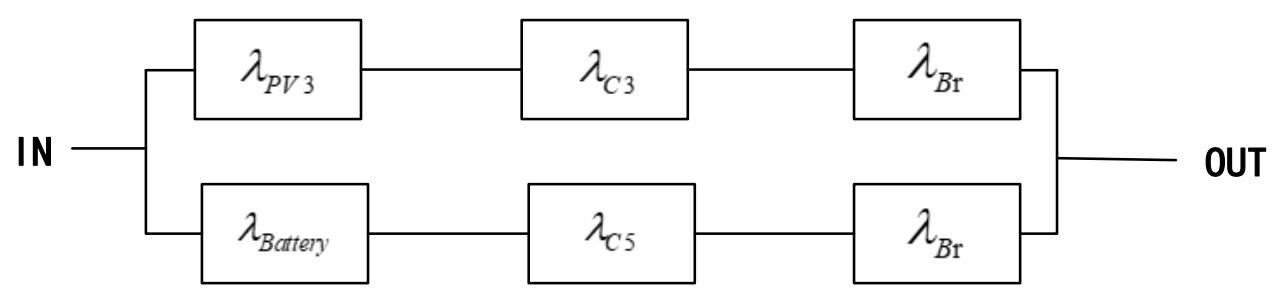

Figure 3-12 RBD of the micro-grid to support load 7,8,9

For subsystem 5 which includes load 10,11,12:

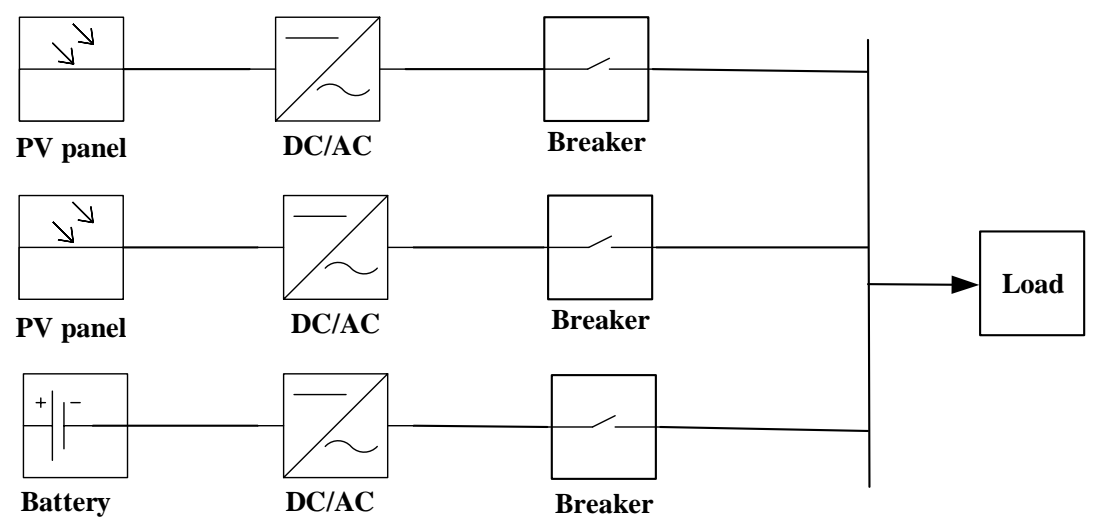

Figure 3-13 Micro-grid diagram for supporting load 10,11,12

RBD of subsystem 5:

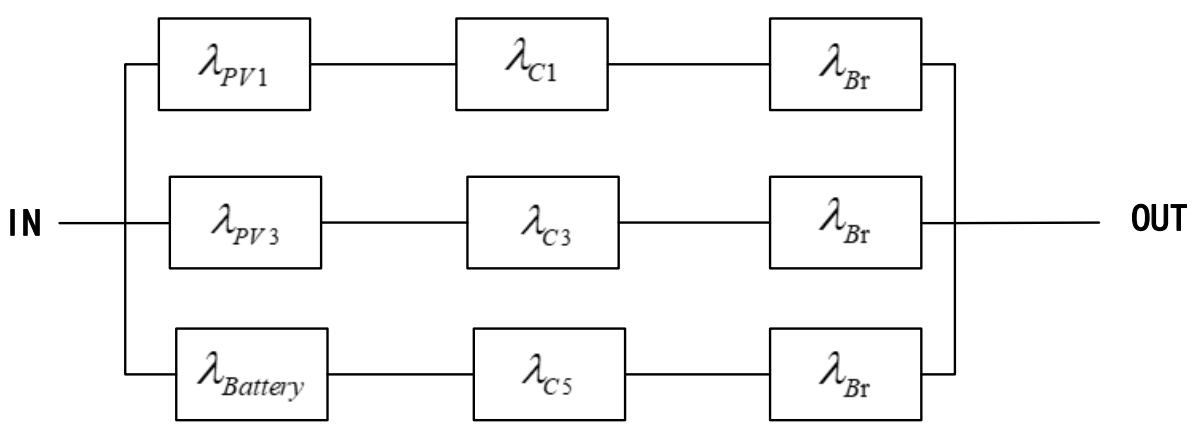

Figure 3-14 RBD of the micro-grid to support load 10,11,12

Next, the energy availability for this microgrid system is calculated. The 24-hour wind speed, ambient temperature and illumination for Milwaukee in 2011 were used and given below: For $\mathrm{LP}_{\mathrm{i}}(\mathrm{i}=1,2, \ldots \mathrm{N})$ 

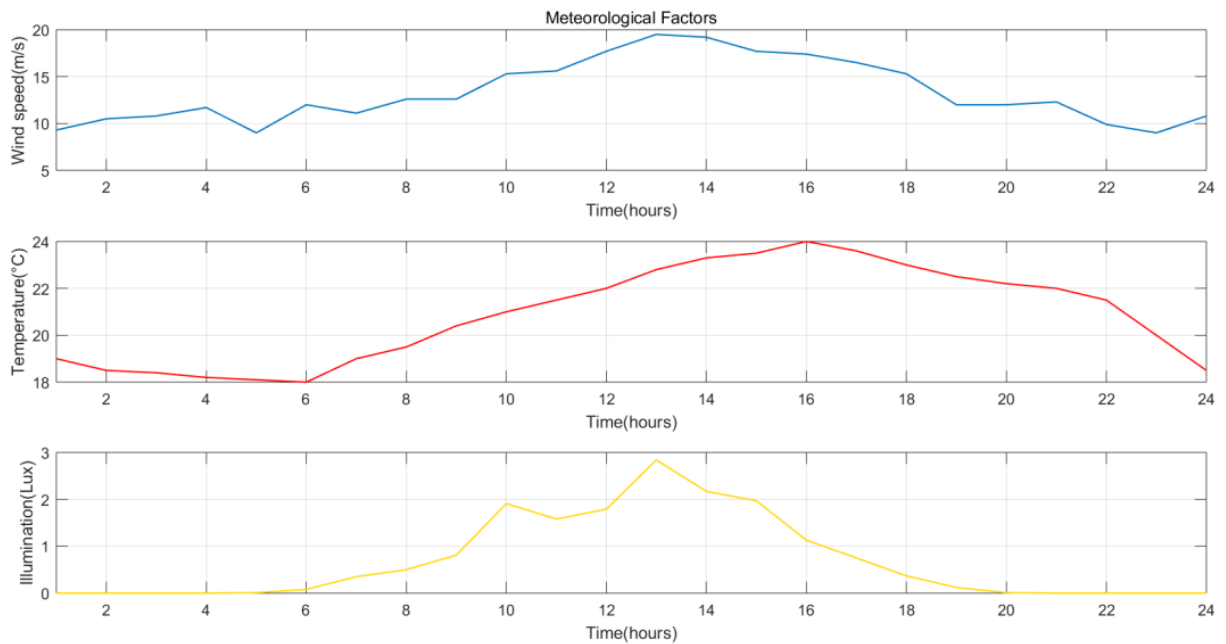

Figure 3-15 Meteorological conditions during the day in summer Milwaukee

The curve above is the wind speed, ambient temperature and illumination. We can find that the peak of the wind speed and illumination are both at 13:00 and the peak of the ambient temperature is at 16:00.

The real-time availability for the wind turbine converters is calculated below:

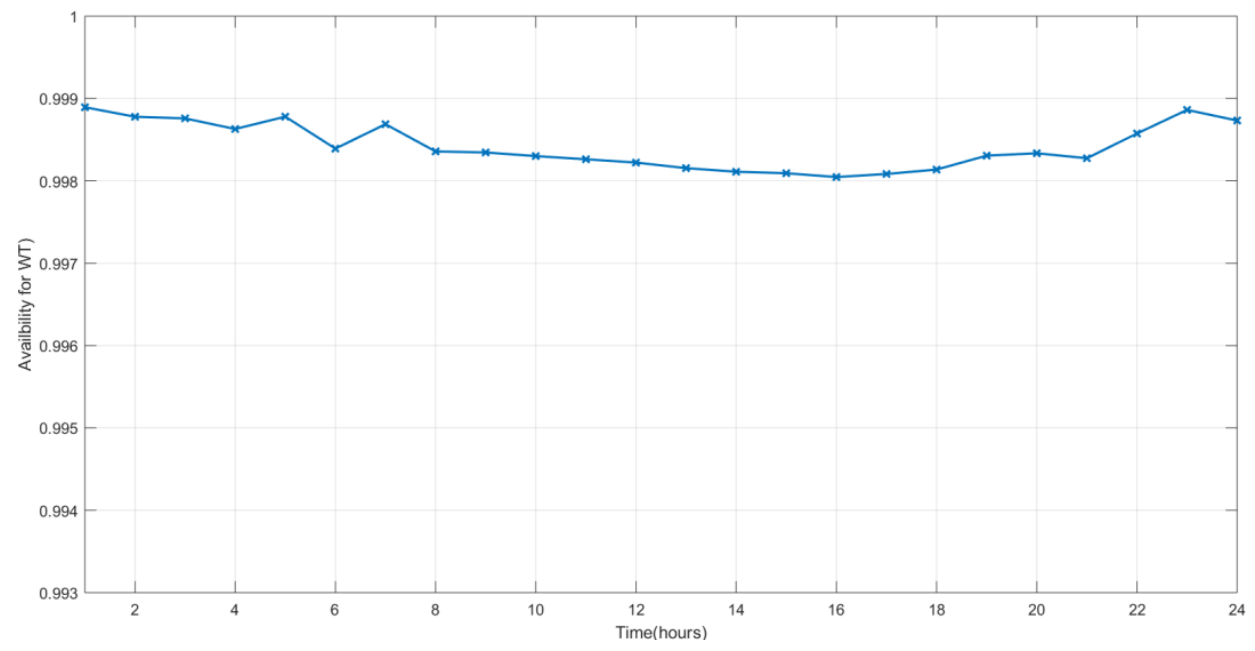

Figure 3-16 Availability for wind turbine converter

The real-time availability for the PV converters is calculated below: 


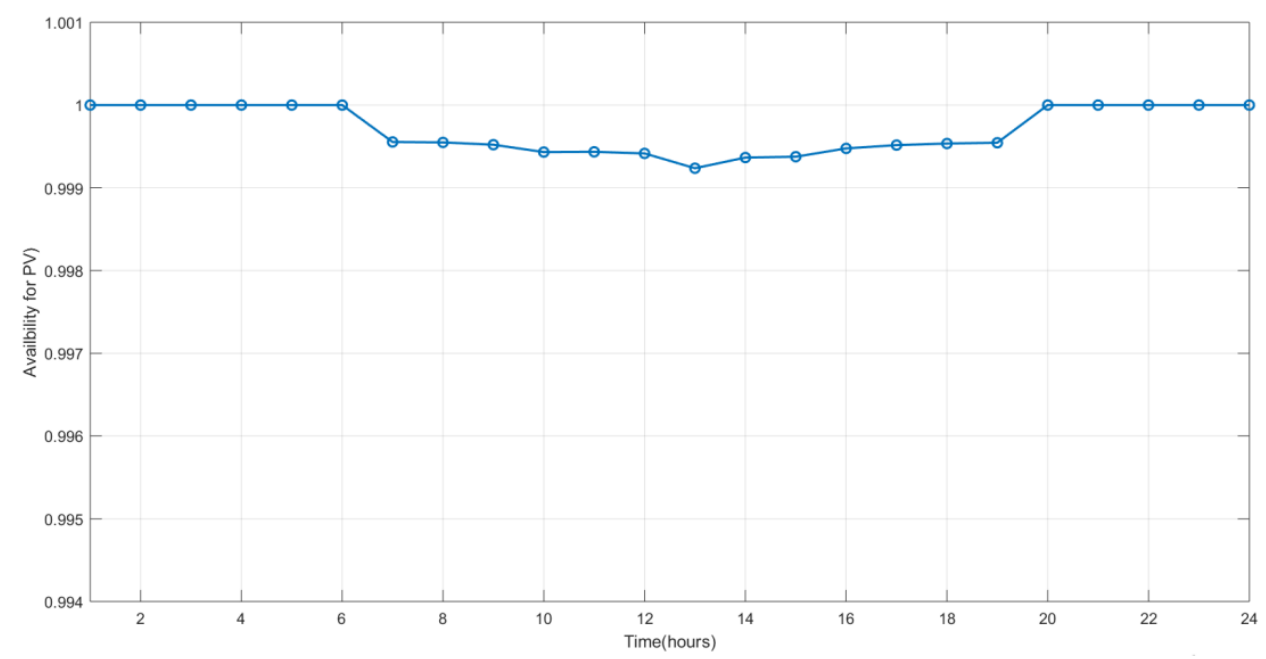

Figure 3-17 Availability for PV converter

The real-time availability for the ES converters is calculated below:

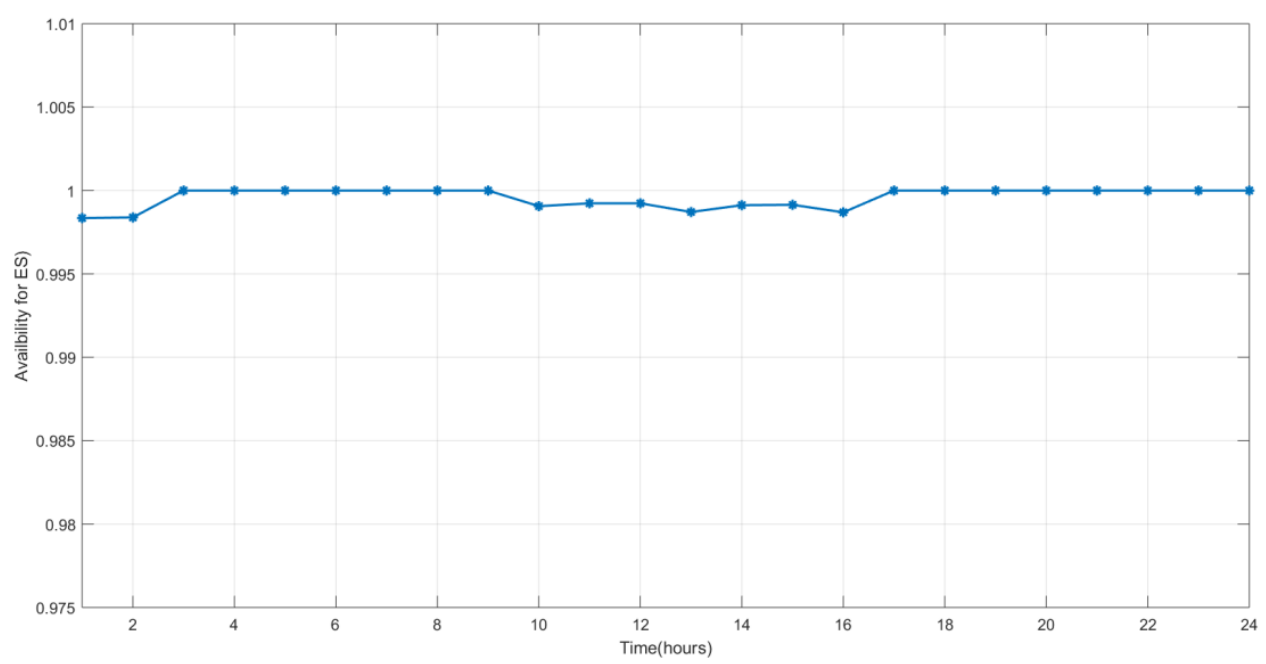

Figure 3-18 Availability for ES converter

From the curves above we can find that, the availability of converter almost has the opposite trend with the failure rate curve of it. For the wind turbine converter, it reaches its lowest point at 16:00 due to the highest failure rate at that time. For the PV converter, it reaches its lowest point at 13:00 also due to the highest failure rate because of the high illumination. For the ES converter which reaches its lowest point at 1:00 due to the highest failure rate at that time.

By using the concept of RBDs, the MTTFs of the five subsystems in Figure 3-5 to Figure 
3-14 are calculated in (3.3)-(3.7), where $\lambda_{1}, \lambda_{2}, \lambda_{3}$ are the lumped failure rate for three PV arrays subsystems with PV, DC/AC, and breaker, respectively. $\lambda_{4}$ is the failure rate for the wind turbine subsystem with wind turbine, AC/DC, DC/AC, and breaker, and $\lambda s$ is the lumped failure rate of the energy storage system. Since the structure of the PV, Wind and ES subsystems are all in series, their lumped failure rate are the sum of power electronic converters, breakers and sources itself.

Therefore, the mean time to failure of the sub-systems above are computed below:

$$
\begin{aligned}
& \operatorname{MTT} F_{d l l}=\frac{1}{\lambda_{1}} \\
& M T T F_{a 12 l}=\frac{1}{\lambda_{1}}+\frac{1}{\lambda_{3}}+\frac{1}{\lambda_{4}} \frac{1}{\lambda_{1}} \lambda_{3} \frac{1}{\lambda_{1}} \frac{1}{\lambda_{4}+\lambda_{3}} \frac{1}{\lambda_{4}+\lambda_{1}+\lambda} \\
& M T T F_{13 l}=\frac{1}{\lambda_{2}} \\
& M T T_{d l} F_{4 l}=\frac{1}{\lambda_{1}}+\frac{1}{\lambda_{5}} \frac{1}{\lambda_{1}+\lambda} \\
& M T T F_{d 5 l}=\frac{1}{\lambda_{1}}+\frac{1}{\lambda_{2}}+\frac{1}{\lambda_{5}} \frac{1}{\lambda_{1}} \lambda_{2} \frac{1}{A_{1}} \frac{1}{\lambda_{5} \quad \lambda_{2}} \frac{1}{\lambda_{5}^{\prime}+\lambda_{1}+\lambda}
\end{aligned}
$$

Then, for the five subsystem, the real-time availability for the five subsystem converters is calculated below: 


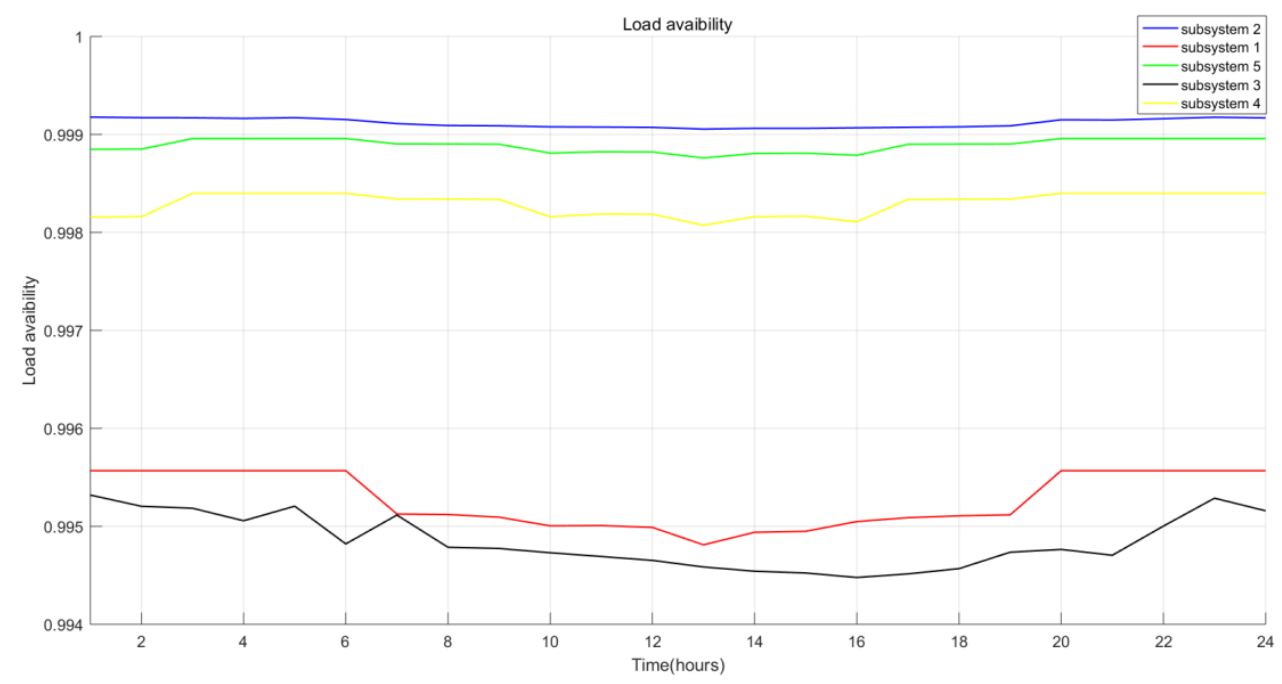

Figure 3-19 The load avaibility for different subsystems with the effect of power electronics

From the curves above we can find that, the five lines except the black one have the same trend, and both reach their lowest point at 13:00. This is because of the high illumination at that time. The black one reaches its lowest point at 16:00 because of the high temperature at that time.

In addition, the availability sequence is acquired by the curve above, which is:

$$
\text { subsystem } 2>\text { subsystem } 5>\text { subsystem } 4>\text { subsystem } 1>\text { subsystem } 3
$$

It's not difficult to find that in microgrid, the more micro-sources the subsystem has, the higher availability they are.

In order to observe the impact of power electronics, the five subsystem availability indices are calculated again only considering the failure rate of the wind turbine, PV arrays and the battery, and the indices are shown below: 


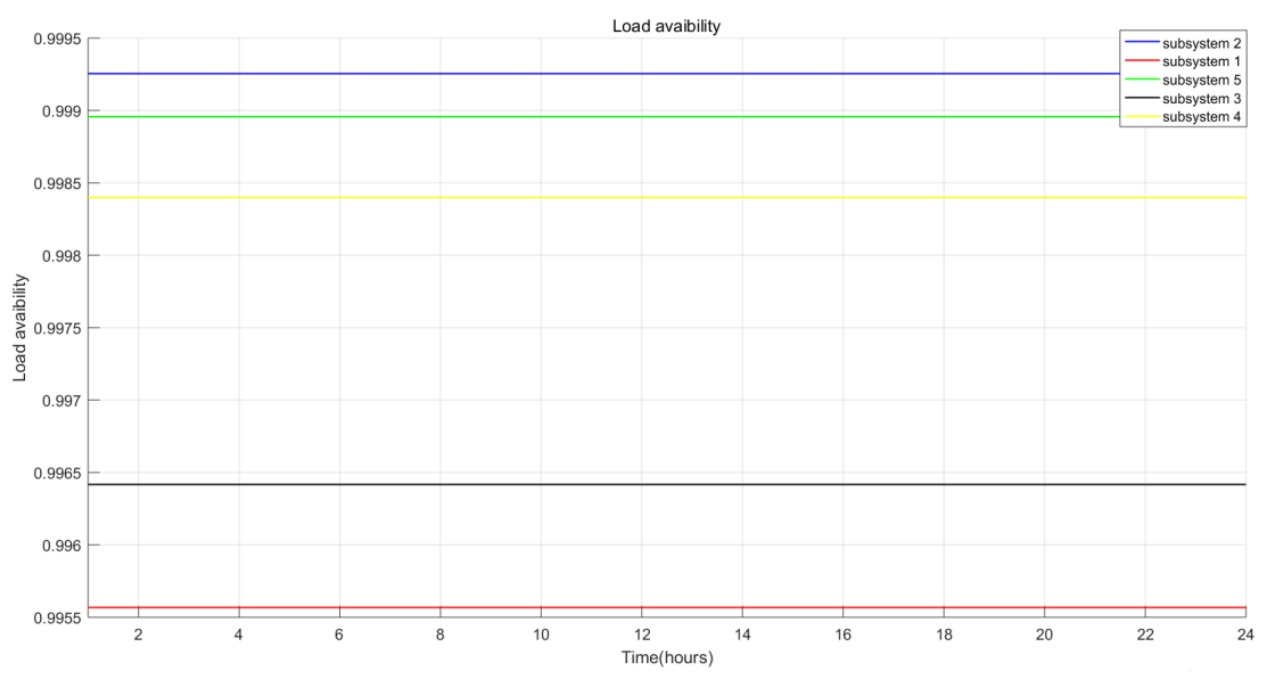

Figure 3-20 The load availability for different subsystems without the effect of power electronics

In Figure 3-19 and Figure 3-20, it can be seen that in the two cases, results of each availability are different. Without consideration of power electronics, the availability indices didn't fluctuate at all. Moreover, the availability order among the five sub-system also change. Although it still shows that sub-system with more micro-sources has higher availability, for the sub-system with the equal number of micro-sources, the results largely depend on the effect of power electronics. Take subsystem 1 and subsystem 3 for example, the availability for subsystem 1 is higher than that of subsystem 3 when the failure rates of power electronics are considered, because when the power electronics are considered, the total failure rate of subsystem 1 is lower thus the MTTF is larger, making the availability of subsystem1 larger than subsystem3.

From the analysis above, it can be seen that availability are largely influenced by power electronics which is a nonnegligible factor that should be considered.

\subsection{The short-term model}

In this paper, considering the failure rates of power electronics which are obtained in previous work, the reliability of the whole microgrid can be evaluated. Since the failure rates of 
power electronics change all the time due to the intermittent output of micro-sources, we use operational reliability indices that can reflect the influence of power electronics in different operational phases clearly.

Before we apply the short-term outage model, the definition of electrical distance should be made first. Electrical distance is the priority rule used to determine the load recovery sequence: try to restore the significant load points in the short electrical distance of the standby power source first. The electrical distance $Z_{i j}$ is defined as the accumulated value of series impedances of the feeders between $L P_{i}$ and standby power source $G_{j}[35]$ :

$$
Z_{i j}=\sum_{l \in \Lambda}\left(R_{l}+j X_{l}\right)
$$

where $R_{l}$ and $X_{l}$ are the resistance and reactance of feeder $l ; \Lambda$ is the set of the feeders between $L P_{i}$ and $G_{j}$.

A short-term outage model is used to calculate system short-term reliability indices in microgrids, specifically, it establishes correspondence between the failure rate of each micro-source with the outage time of each load point by system repair time matrix. And the system repair time matrix is determined according to the available capacity, load demand and electrical distance. Detailed steps are given as follows:

Step 1) Determine the available capacity of $G_{j}$ during $\Delta t$.

Step 2) According to the electrical distance $\left|Z_{i j}\right|$, the node impedance matrix and load recovery sequence of the system for each $G_{j}$ are generated. For load points with the same $\left|Z_{i j}\right|$, the important one is recovered with higher priority. 
Step 3) If $G_{j}=0$, go to step 5; otherwise, go to step 4 .

Step4) If $G_{j}>0$,

For the load with higher priority, if $G_{j} \geq l o a d_{-} r e a l-l o a d_{-} t$, then $l o a a_{\_} t=l o a d \_r e a l$, and $G_{j}=G_{j}-\left(l o a d \_r e a l-l o a d \_t\right)$. Where load_real is the ideal value of the load, while load_t is the intermediate calculated values of the load at time t. Otherwise, $l o a a_{-} t=l_{0 a d_{-}} t+G_{j}$ and $G_{j}=0$.

For the load with low priority, the load has nothing to do with generation, all power generation is stored in the energy storage system, $E_{e}=E_{e}+G_{j}$, and $G_{j}=0$.

Step 5) If $E_{e}>0$, for the load with high priority, if $E_{e} \geq l o a d_{-}$real-load_t $t$, then loaa_t $=$ load_real , and $E_{e}=E_{e}-\left(l o a d_{-}\right.$real-load_t $)$. Where load_real is the ideal value of the load, while load_t is the intermediate calculated values of the load at time $t$. Otherwise, $l o a a_{-} t=l o a d_{-} t+E_{e}$ and $E_{e}=0$.

Step 6) $i=i+1$, or move to the next load point in the sequence of $G_{j}$, and then go to step 3 .

Step 7) If $j<N_{G},\left(N_{G}\right.$ is the number of standby power sources $)$, then $\mathrm{j}=\mathrm{j}+1, i=1$, and then go to step3; otherwise, end the process.

Through the approach above, the load recovery sequence as well as the repair time matrix can be obtained.

Then, I use the short-term model in reference [14] to calculate the test system's average short-term outage time, average failure rate and outage time. The model can be expressed in following formulas: 


$$
\begin{gathered}
{\left[\begin{array}{c}
U_{1} \\
U_{2} \\
\vdots \\
U_{N}
\end{array}\right]=\left[\begin{array}{cccc}
r_{11} & r_{12} & \cdots & r_{1 M} \\
r_{21} & r_{22} & \cdots & r_{2 M} \\
\vdots & \vdots & \cdots & \vdots \\
r_{N 1} & r_{N 2} & \cdots & r_{N M}
\end{array}\right] \cdot\left[\begin{array}{c}
\lambda_{1} \\
\lambda_{2} \\
\vdots \\
\lambda_{M}
\end{array}\right]} \\
h(i, j)= \begin{cases}0, & r_{i j}=0 \\
1, & r_{i j}>0\end{cases} \\
\lambda_{L P, i}=h(i,:) \cdot\left[\begin{array}{c}
\lambda_{1} \\
\lambda_{2} \\
\vdots \\
\lambda_{M}
\end{array}\right], \quad i=1,2, \cdots, N \\
r_{L P, i}=\frac{U_{i}}{\lambda_{L P, i}}, \quad i=1,2, \cdots, N
\end{gathered}
$$

And the short-term reliability indices are described as follows by using the parameters obtained above:

$$
\begin{aligned}
& \text { SAIFI }=\frac{\sum_{i=1}^{N} \lambda_{L P, i} m_{i}}{\sum_{i=1}^{N} m_{i}} \\
& \text { SAIDI }=\frac{\sum_{i=1}^{N} U_{i} m_{i}}{\sum_{i=1}^{N} m_{i}} \\
& \text { ENS }=\frac{\Delta t \sum_{i=1}^{N} L_{i}}{\sum_{i=1}^{N} m_{i}}
\end{aligned}
$$

The evaluation procedure is given in the following flowchart: 


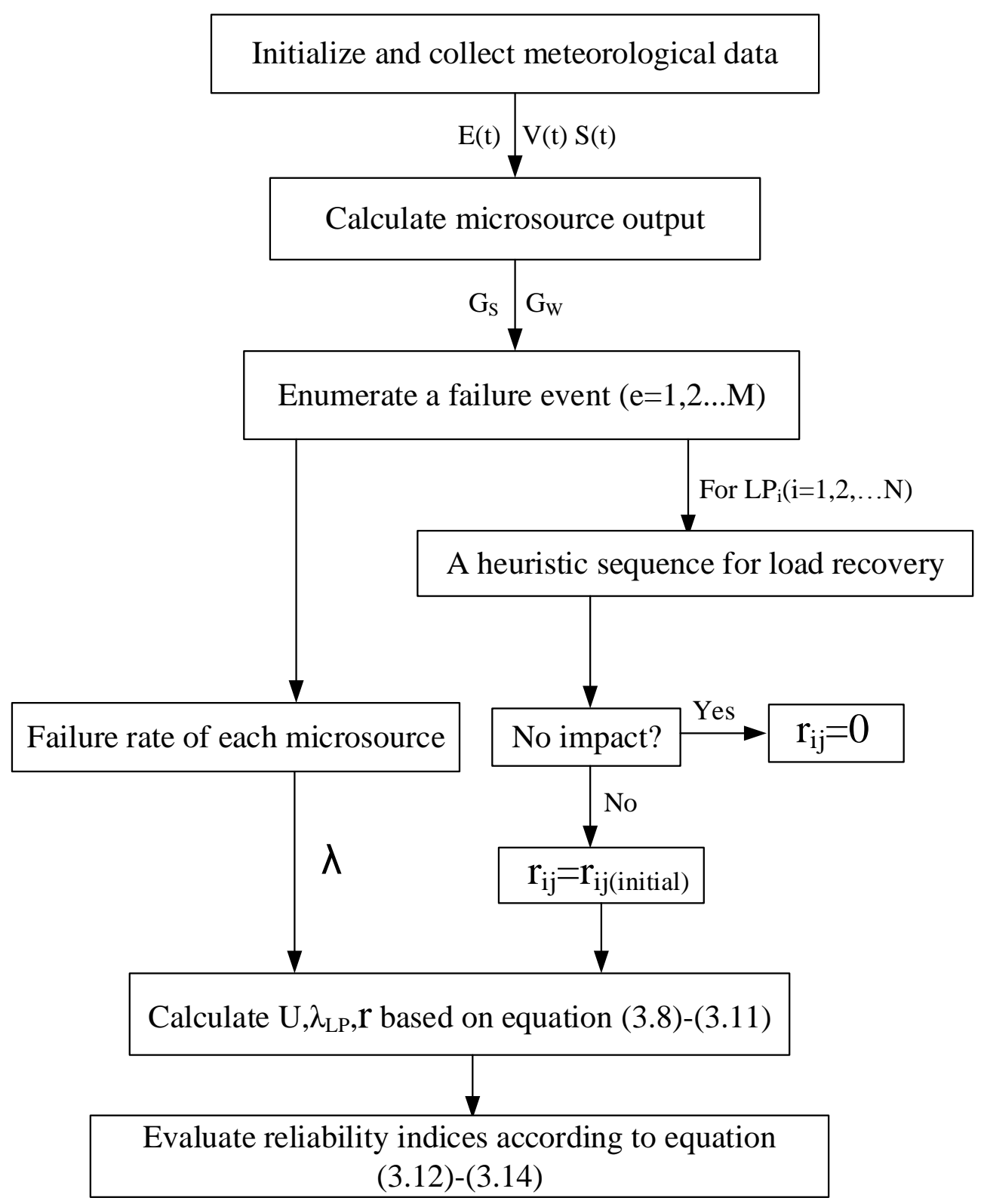

Figure 3-21 Flowchart of the evaluation procedure

Following cases are studied to consider the effects of power electronics, micro-sources' number and type on the reliability of microgrid.

\begin{tabular}{ccc}
\hline & Effect of power electronics & Micro-sources included \\
\hline Case1 & Yes & 3 PVs+wind trubine \\
Case2 & No & 3 PVs+wind trubine \\
\hline
\end{tabular}




\begin{tabular}{ccc}
\hline Case3 & Yes & 3 PVs \\
Case4 & Yes & 3 PVs+ PVs \\
\hline
\end{tabular}

Table 3-4 Four cases under different conditions

Case 1 and Case 2 comparison result:
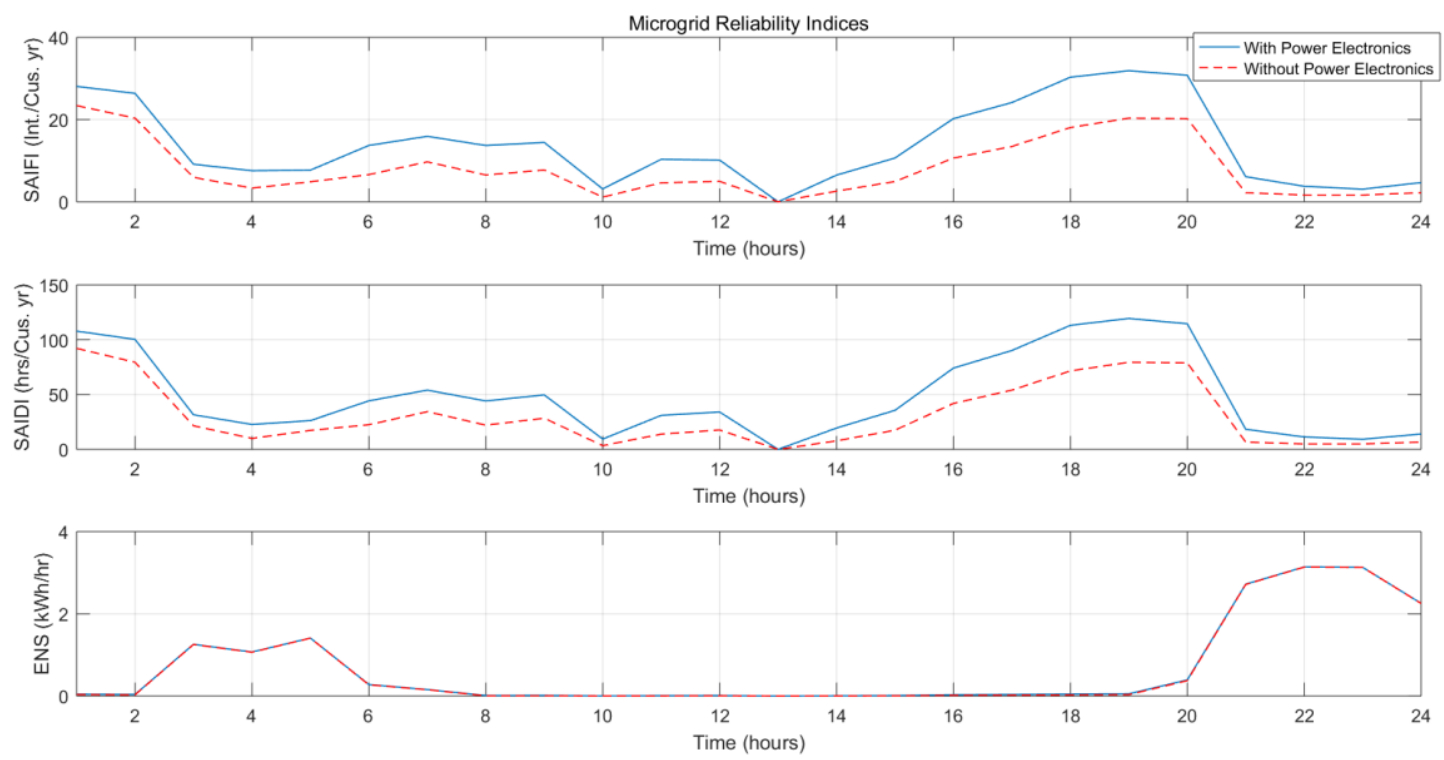

Figure 3-22 Microgrid reliability indices of case 1 and case 2
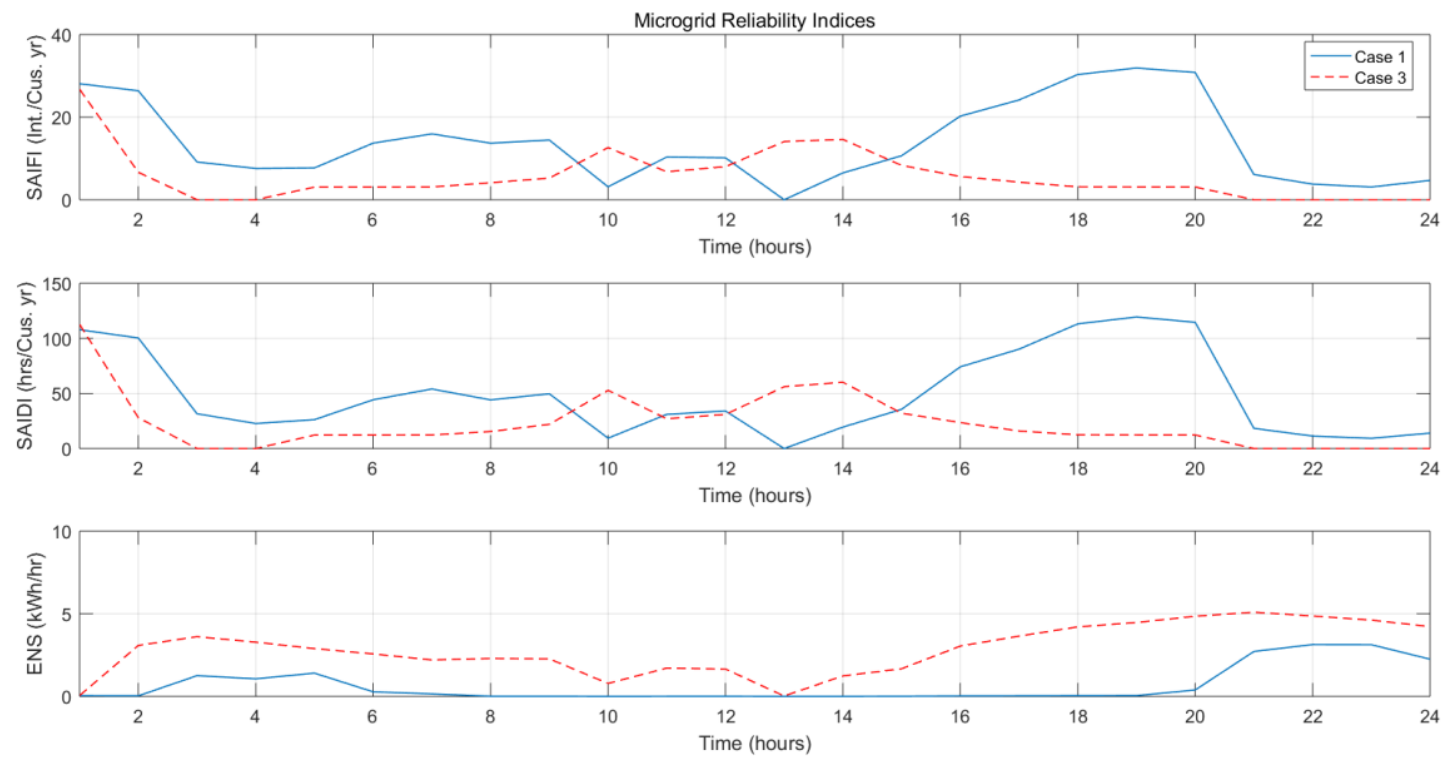

e 3-23 Microgrid reliability indices of case 1 and case 3 


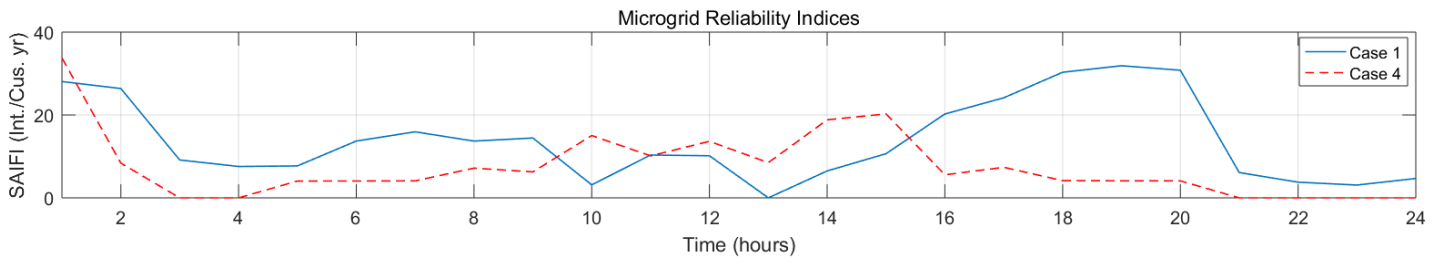

Figur
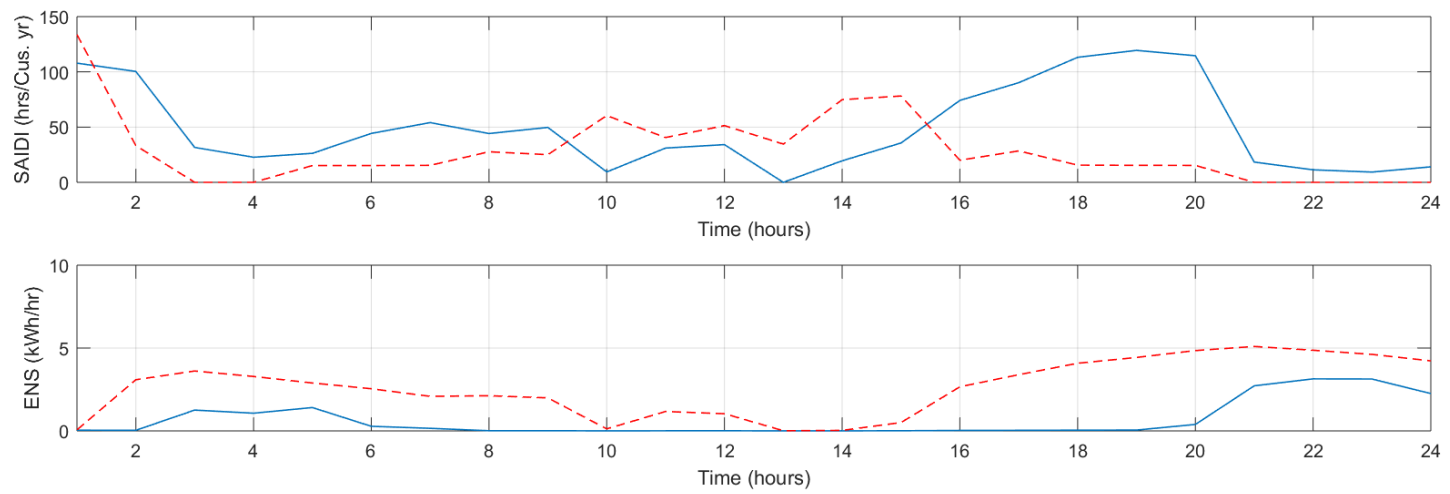

Co

$\mathrm{mp}$

aris

on of system reliability indices:

\begin{tabular}{cccc}
\hline $\begin{array}{c}\text { Reliability } \\
\text { indices }\end{array}$ & SAIFI(int/cus-hour) & SAIDI(hr/cus-hour) & ENS(kWh/hour) \\
\hline Case 1 & 11.3479 & 41.6513 & 1.0963 \\
Case 2 & 7.2530 & 27.7158 & 1.0874 \\
Case 3 & 5.6032 & 22.7665 & 2.8420 \\
Case 4 & 7.3489 & 28.7240 & 2.6054 \\
\hline
\end{tabular}

Table 3-5 Comparison of system reliability indices

1) In case 1, SAIFI and SAIDI reach their lowest point at 13:00, this is because total available capacity at that time is highest of the whole day. Meanwhile, total failure rate of each micro-source is another important factor for SAIFI and SAIDI, verified from the case 3 and case 4. For example, between $t=9: 00$ to $t=15: 00$, because the PV converver's failure rate are in a high level and the total capacity of generatonrs in case 3 and case 4 reduce as well, resulting in a rise of SAIFI and SAIDI campare with case 1. 
2) Compare between case 1 and case 2, although the values of ENS do not change significantly, there is a noticeable change in SAIDI and SAIFI values which are larger when the failure rates of power electronics are taken into account, this is because under the consideration of power electronics, the total failure rate of each micro source is larger and the outage time for each load is larger, so that SAIFI and SAIDI are larger. The comparison between case 1 and case 2 indicates that power electronics have a significant impact on the microgrid operational reliability indices, especially SAIFI and SAIDI. In other words, if they are not taken into account, the reliability estimate will be more conservative.

3) The number of micro-sources have a positive effect on the average loss of load(ENS) which can be verified by comparing case 1 with case 3 , or also the different between case 3 and case4. This is because the generation capacity which is the determining factor of ENS are larger with more micro-sources; On the other side, more micro-sources represent larger component failure rates, result in rising in SAIFI and SAIDI.

4) Compared with case 1 , case 4 changes the micro-source type at No. 6 bus from a wind turbine generator to a photovoltaic array. SAIFI and SAIDI reduce due to the failure rate of PV converter are less than WTG converter, and ENS rises, because the capacity of WTG are larger and more stable than PV, resulting in Energy Not Supply are lower than that of PV. In other words, the types of micro-sources should be elaborately designed according to the needs of the system while planning the microgrid system. 


\section{Chapter 4 Sensitivity Analysis}

\subsection{The effect of wind turbine parameter setting}

The parameter setting of the wind turbine, such as cut-in speed, cut-out speed and rated speed plays an important role in not only the wind generation but also the reliability of the components. In this section the influence of them are studied.

First, based on the 24-hour wind speed we used in the previous, the average hourly wind generation are calculated under the situation of different cut-in wind speed.

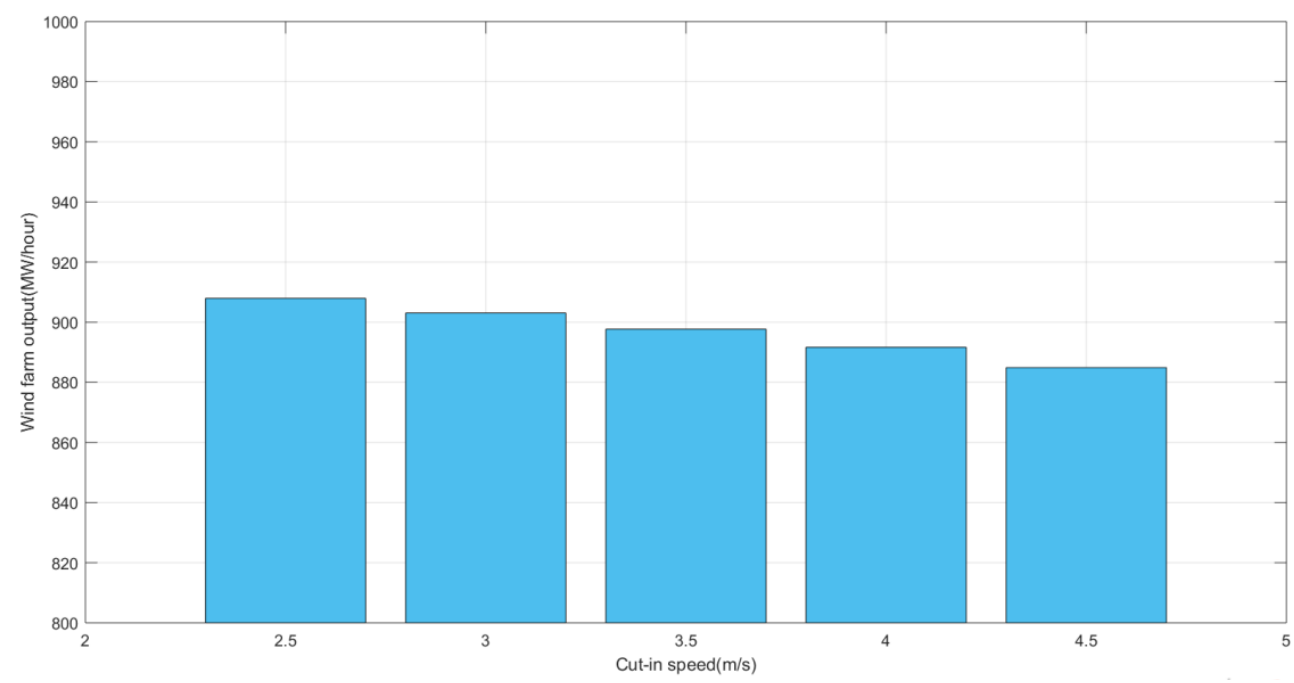

Figure 4-1 Average hourly wind generation

As we can see above, with the cut-in speed increase, the hourly generation capability of wind turbine will produce corresponding reduce. The availability of the converter is also calculated as well: 


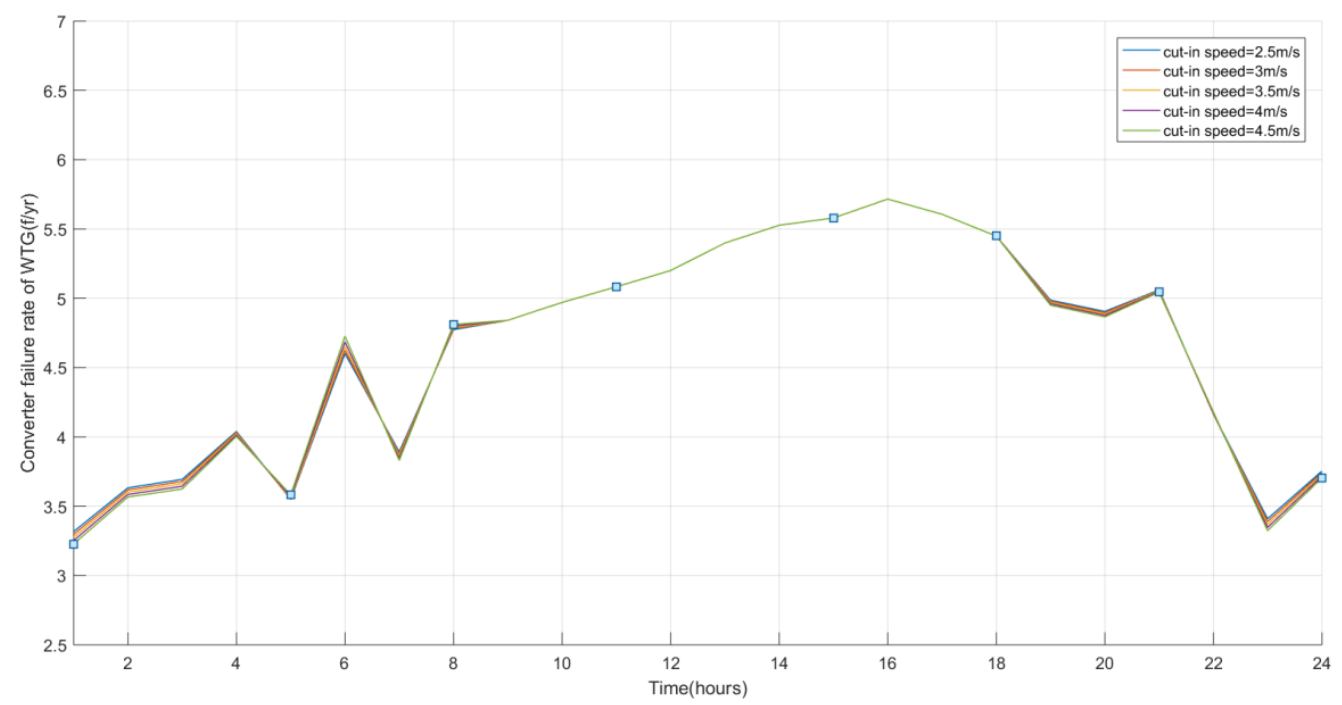

Figure 4-2 Converter failure rate

It can be concluded from above figure that the real-time failure rate for the converter is affected by the cut-in speed. Specifically, when the wind speed is low, the influence is notable while the wind speed reaches the rated speed there is no influence.

Similarly, the average hourly wind generation under different rated wind speed were calculated again as below:

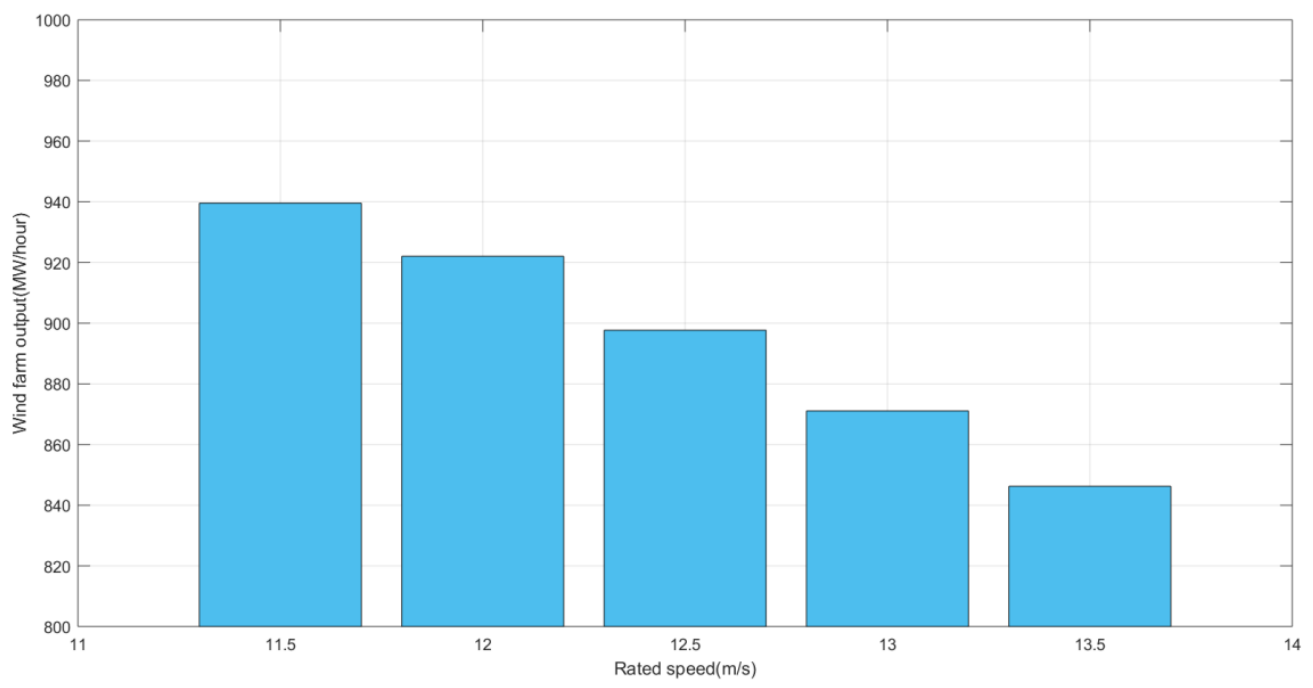

Figure 4-3 Average hourly wind generation 
As we can see above, with the rated speed increase, the hourly generation capability of wind turbine drops by a large margin. The availability of the converter was also calculated again:

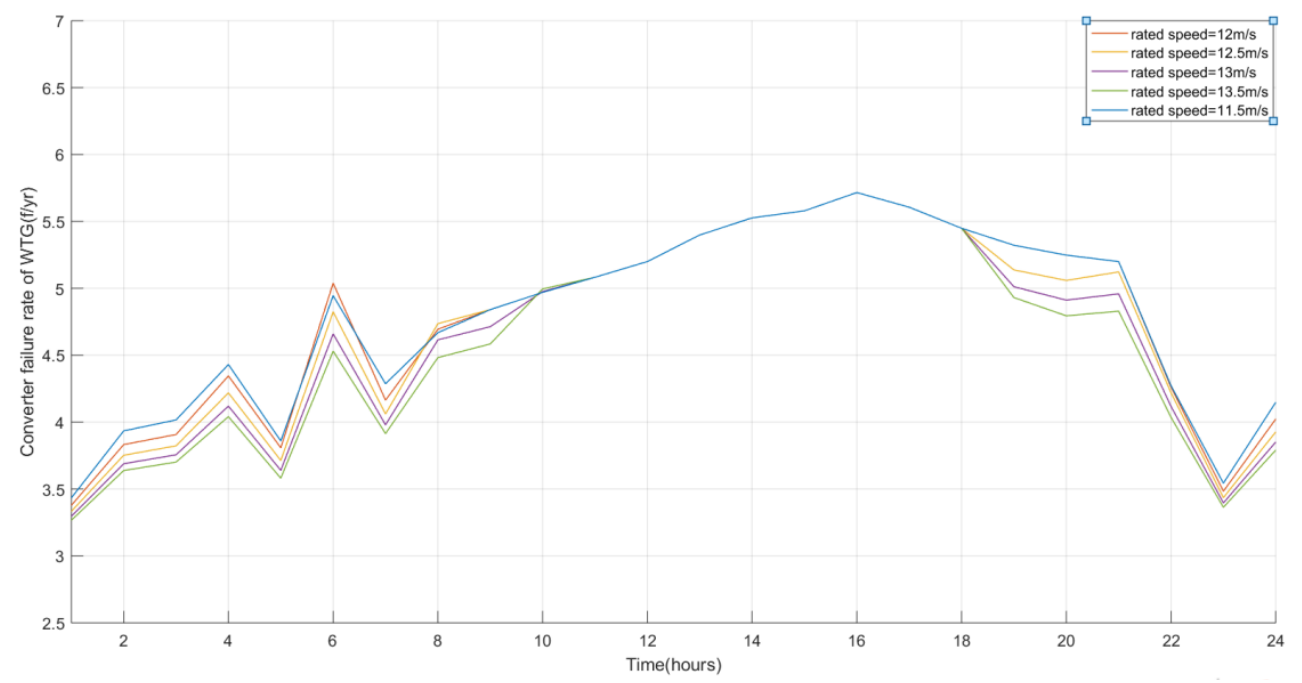

Figure 4-4 Converter failure rate

As shown above, the real-time failure rate of the converter changes as the rated speed changes. Specifically, when the wind speed is lower than rated wind speed, the effect is significant, however, when the wind speed is larger than the maximum rated wind speed after 10:00 there is no effect.

\subsection{Yearly calculation and seasonal characteristics}

In order to do this analysis, the meteorological data including wind speed, ambient temperature and illumination in each hour during 2010 in Milwaukee is used. 


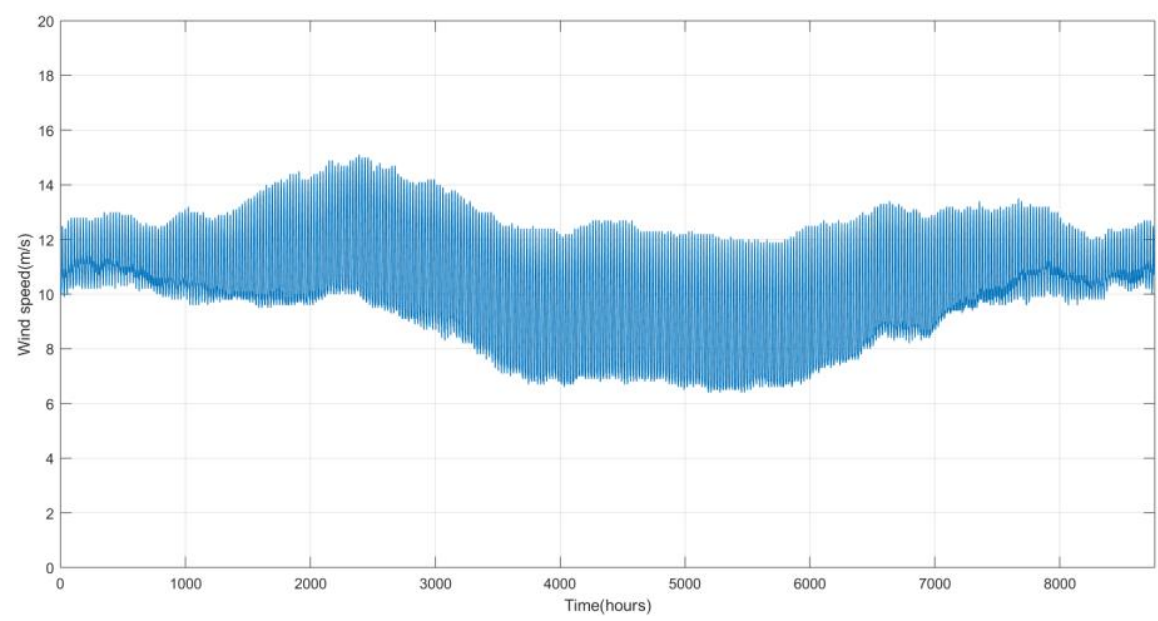

Figure 4-5 Wind speed in Milwaukee, 2010

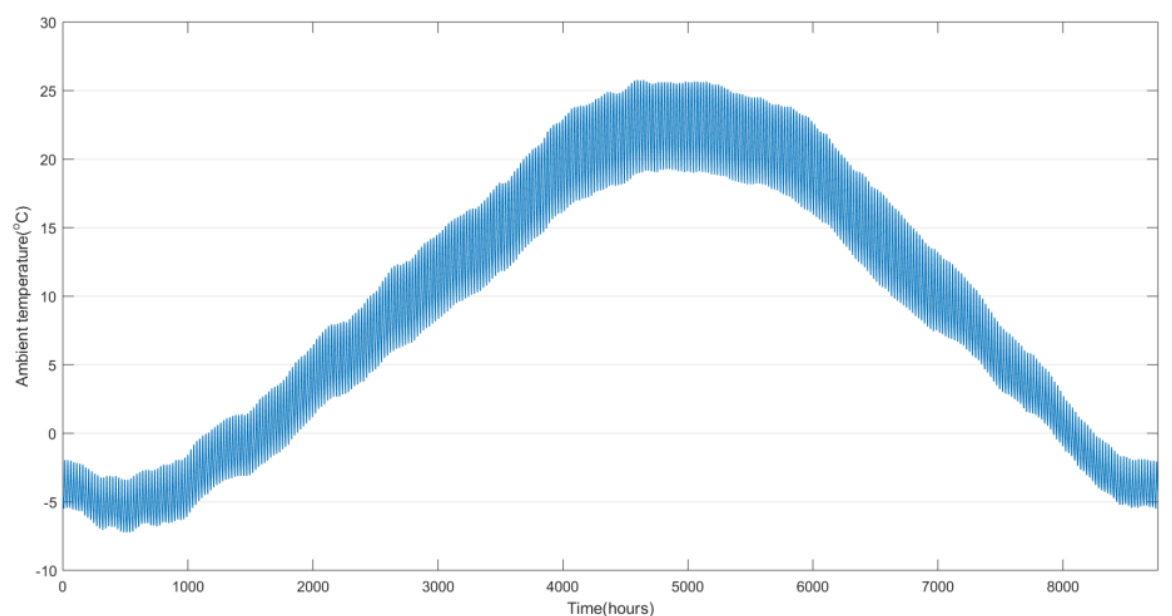

Figure 4-6 Ambient temperature in Milwaukee, 2010

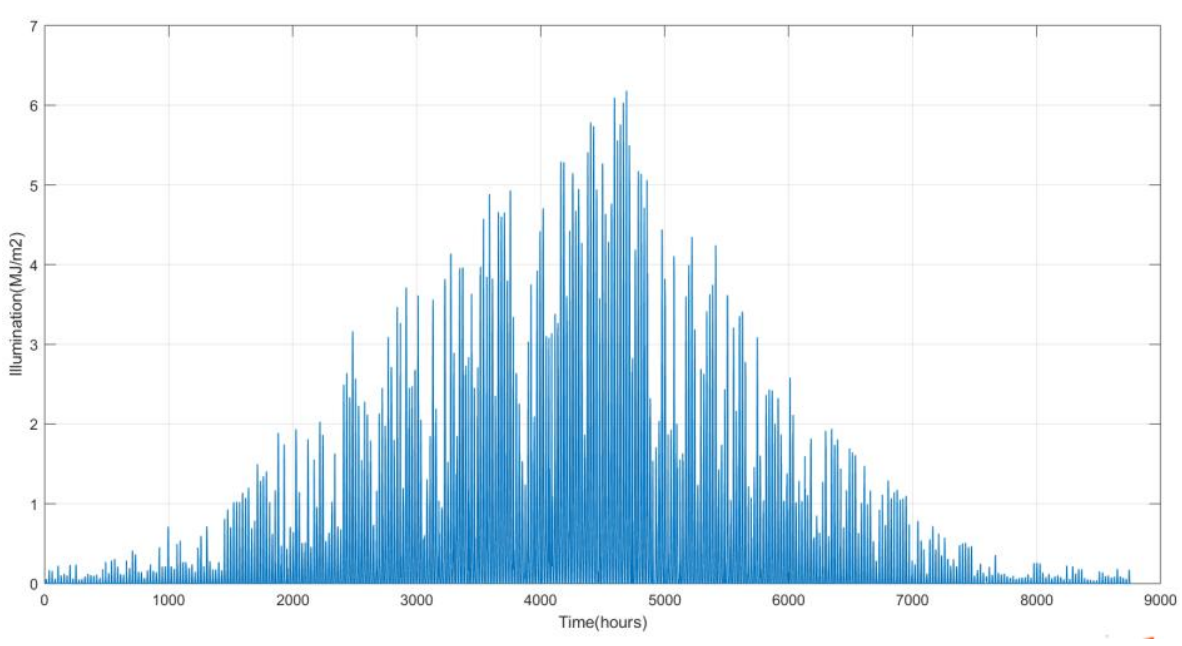

Figure 4-7 Illumination in Milwaukee, 2010 
As we can see above, all the meteorological data have a specific seasonal character. To be more specific, in summer and autumn, the ambient temperature and illumination value are relatively high, and relatively lower in the other seasons. Wind speed just has the opposite situation. Besides, it is not difficult to find that wind speed fluctuations are stronger during summer and autumn.

Next, the whole year wind turbine capacities as well as the real-time failure rate for the converter are calculated.

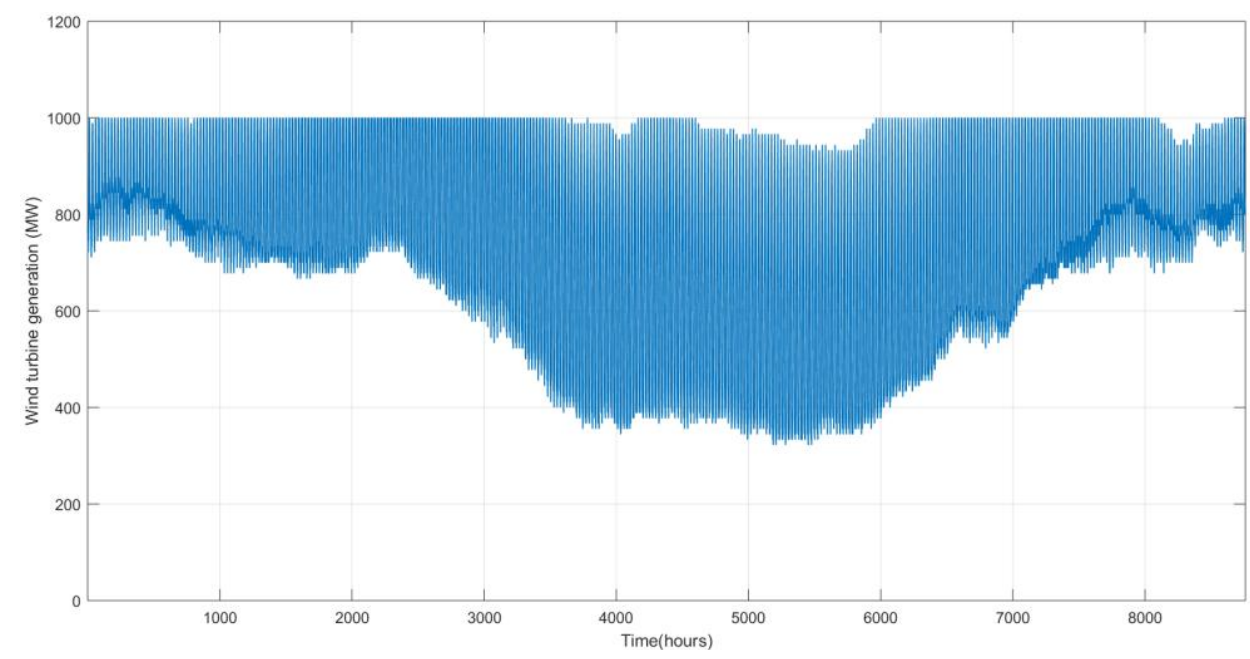

Figure 4-8 Hourly wind generation

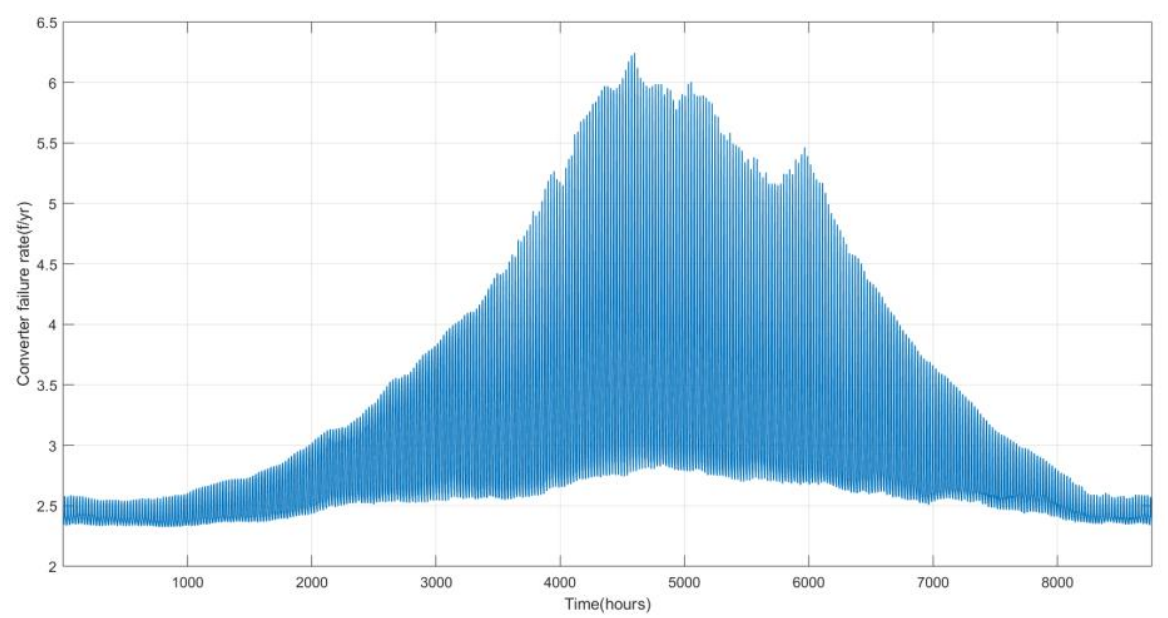

Figure 4-9 Hourly converter failure rate for wind turbine 
As is shown in Figure 4-8, the lowest point for the wind generation is between 3000 hour to 6000 hour. The reason is the wind speed is low during summer and autumn. The hourly converter failure rate curve has the same pattern with that of ambient temperature. In addition, it reflects the intense fluctuation of the wind speed during summer and autumn as well.

In the same way, the annual PV array capacity and the real-time fault rate of the converter are calculated.

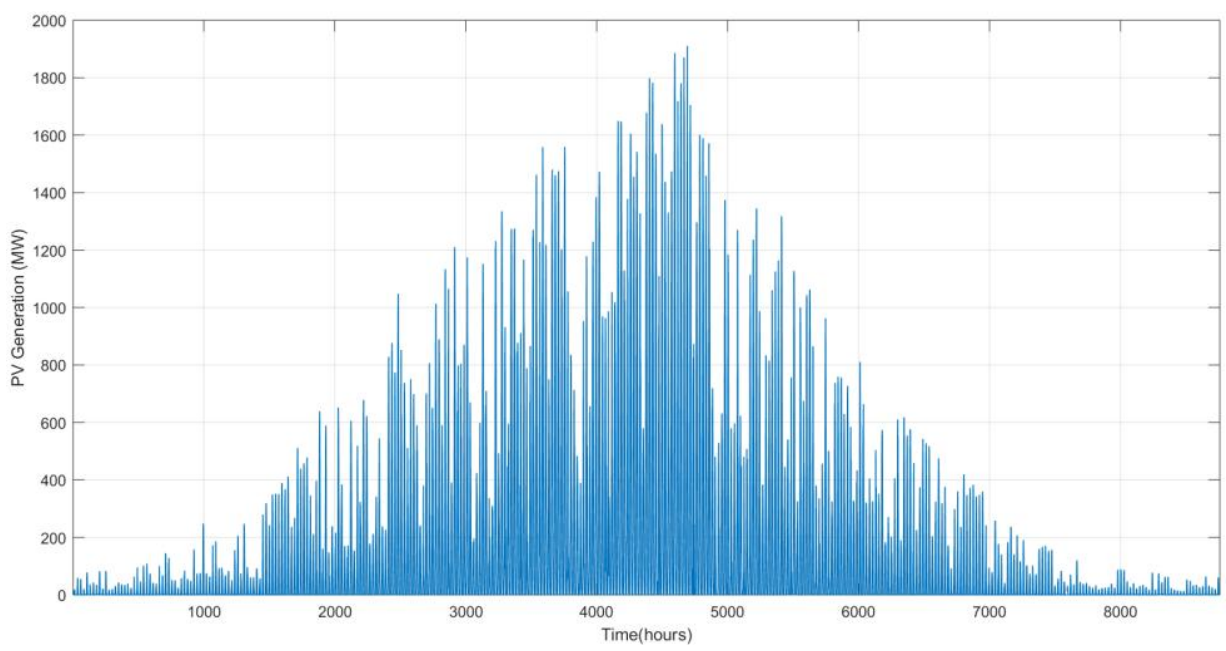

Figure 4-10 Hourly PV generation

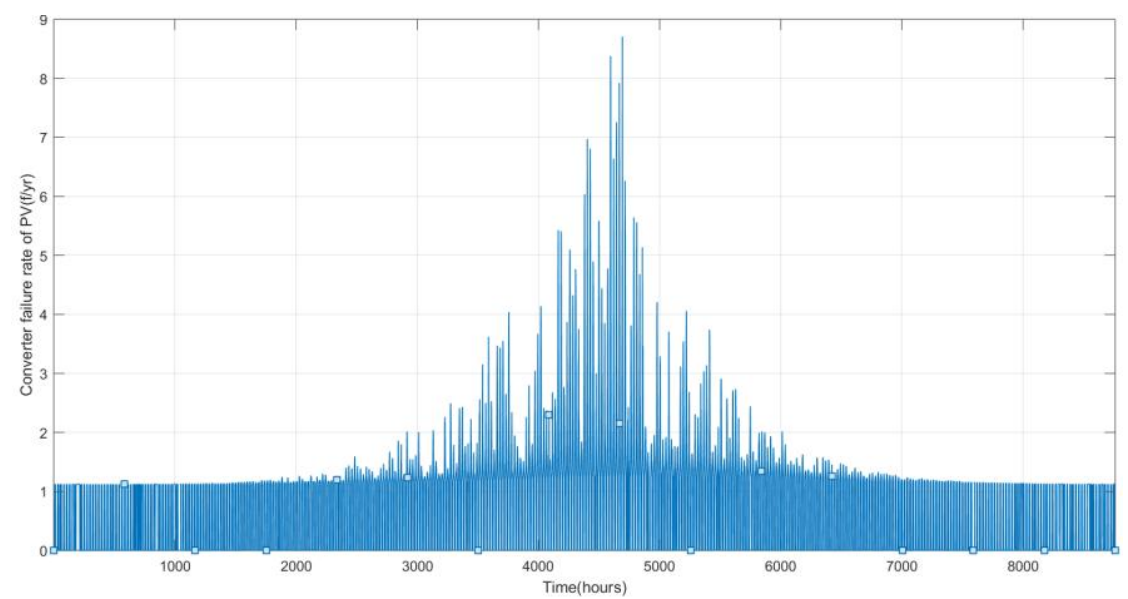

Figure 4-11 Hourly converter failure rate for PV arrays

As we can see above, the highest point for the PV generation is between 4000 hour to 5000 hour as a result of the high illumination in summer. The trend of the hourly converter failure rate 
curve is similar to that of the illumination curve. It reflects that the failure rate is high in summer and low as well as smooth in the rest three seasons.

Then the yearly real-time reliability indices for the test microgrid system are calculated below:
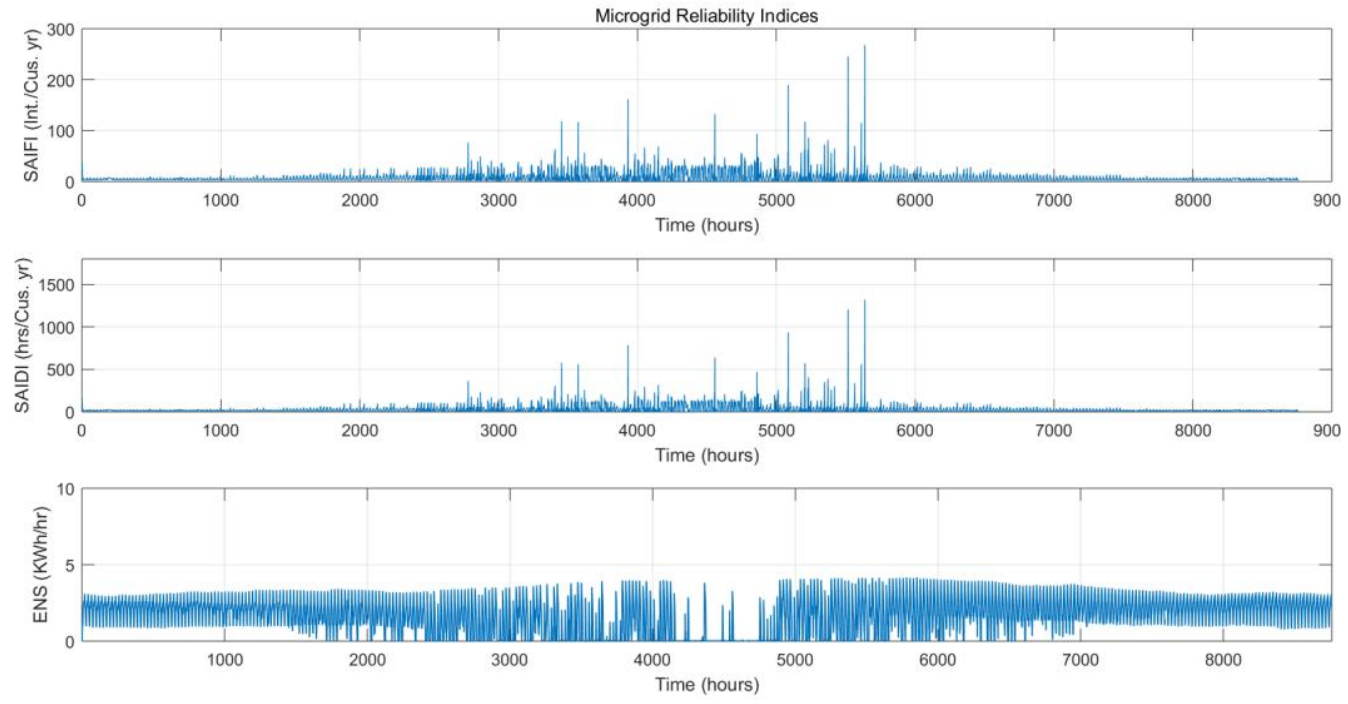

Figure 4-12 Hourly reliability indices for system

As we can see above, the indices of reliability for the teat system are also seasonal. In summer, the system average interruption frequency and duration are significantly higher than that of the other seasons. This is because the high failure rate of converter during summer. For energy not supply(ENS), the curve reveals that the ENS is larger in summer, at the meantime, as the micro-sources supply plentifully, the probability of ENS with a value of 0 is much higher than it is in the other seasons.

\subsection{The effect of meteorological condition}

The meteorological data given in Figure 4-5 to Figure 4-7 are collected in Milwaukee (Northern US). If this microgrid is located in Miami (Southern US), reliability indices(SAIFI) are compared in Figure 4-13. The following conclusions could be easily drawn from this 
comparative study:

1) We can't expect the same reliability even if in the identical microgrid as well as load demands. This is because the operation of the microgrid is also related to the meteorological conditions at its location.

2) The same level of reliability cannot be expected all the year around. As shown in Figure 4-13, this microgrid system has the highest reliability in December.

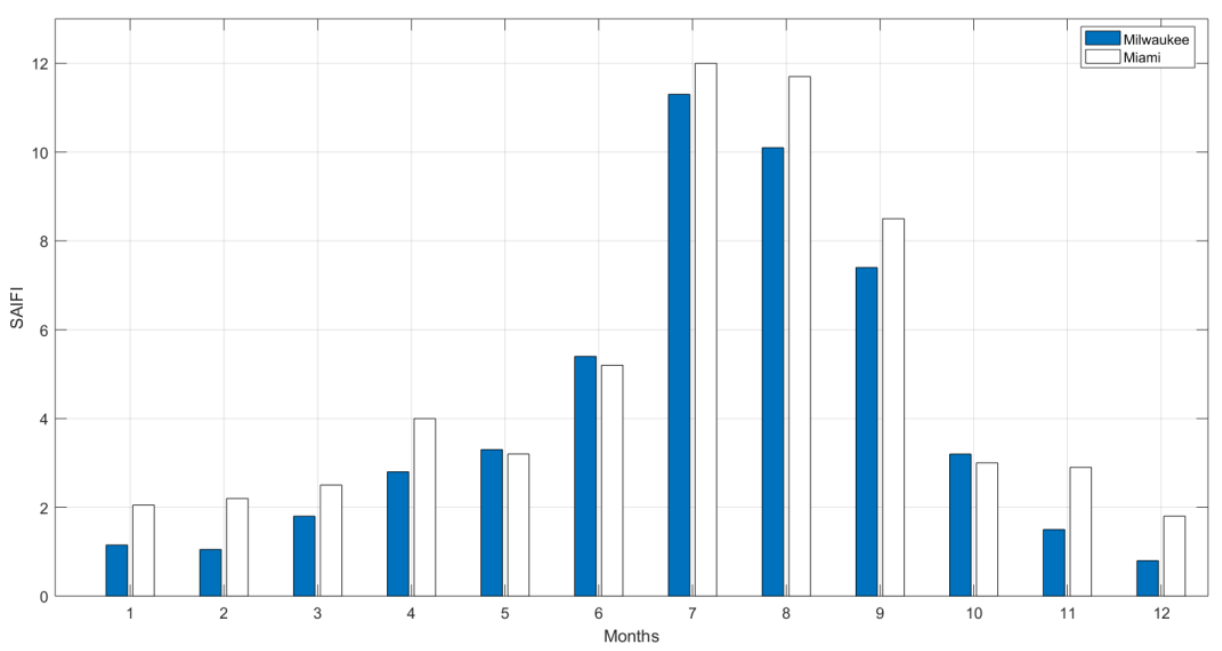


As we can see above, in the comparison case of Milwaukee and Miami, the reliability

indices are better in Milwaukee than that in Miami, indicates that we should establish and develop more microgrids in Milwaukee rather than in Miami. 


\section{Chapter 5 Conclusion}

This thesis studies the operating reliability considered power electronics for the microgrid system. And calculates the reliability indices for a 11-node test system as well.

Firstly, failure rates of power electronics in micro-sources are evaluated by building and testing the real-time failure model which considers the operational conditions and control strategy of the microgrid. The results show that, with the real-time meteorological conditions(wind speed, temperature, illumination)change, the converter for micro-sources failure rate will produce the corresponding change. Specifically, both wind speed and ambient temperature have effect on the failure rate of the wind turbine converter. In the stable operating environment, effect of ambient temperature is very significant and the outage is more likely to happen during the daytime for the sake of the high temperature. For PV converter, in the normal condition, illumination is the most crucial part in the effect of converter failure and the outage will happen during the daytime because of the illumination.

Then, a case study is carried out. First, the 11-nodes microgrid systems are simplified by using the reliability block diagram (RBD) method. And the energy availability are calculated for every sub-system considering the influence of power electronics. The results show that, the availability for each system vary evidently with different operating and environment conditions. Besides, the ambient temperature and the wind speed are the main factors. Then, a short-term outage model is established to calculate SAIFI, SAIDI and ENS of the system under different cases. the result indicates that power electronics have a significant effect on the reliability indices, especially SAIFI and SAIDI. Besides, both the number and type of micro-sources have important 
effect on the reliability indices. In a word, the reliability of microgrid system depends on the available generation capacity, load requirements and the failure rate of the components as well in the system.

Lastly, the sensitivity analyses study relating to the influence of season, wind turbine parameters, and meteorological condition are carried out. The results show that, the seasonal characteristic is significant, and the failure rate is largely affected by the temperature while the wind speed also has its influences. The lowest system energy availability is in the hottest time in the year. Even for microgrids with the identical network and load demands, reliability indices are not the same because that the operation of microgrid is also related to the meteorological condition at its location. To improve the system reliability, we can adjust the wind turbine parameters.

Future work can be focused on the following aspects:

- Considering more weather condition in components' failure model, and studying the impact of extreme weather and its duration on components' real-time failure and on system reliability;

- Building real-time failure rate model for other components in microgrid system, such as switchyard, control system, transmission line and others.

- Integrating climate forecast technology like wind speed, illumination and temperature to the failure rate prediction of the converter and system.

- Calculating the availability of the whole system and analyzing the contribution of each component to the system reliability;

- Conduct more case studies such as a practical system which has more nodes, larger capacity 
and loads, as well as including conventional generation systems such as diesel or natural gas generators which are used to keep the system stable when clean energy are highly intermittent.

- Performing economic analysis when discuss the number and type of micro-source effect; considering the investment and the maintenance to choose the optimal scheme.

- Calculating the system reliability for more systems with different topologies; and considering the connection to the utility and calculating reliability indices in connected modes. 


\section{References}

[1] Ansari, Osama Aslam, Nima Safari, and C. Y. Chung. "Reliability assessment of microgrid with renewable generation and prioritized loads." Green Energy and Systems Conference (IGSEC), 2016 IEEE. IEEE, 2016.

[2] Čepin, Marko. "Assessment of power system reliability: methods and applications," Springer Science \& Business Media, 2011.

[3] Shi, Xiaofang. "Micro-grid Reliability Modeling and Analysis Approaches.", 2016.

[4] Microgrids-the next evolution of the grid. (2014, November 2). Retrieved May 4, 2018, from: http://www.solup.com/microgrids-next-evolution-grid/.

[5] F. Z. Peng, Y. W. Li and L. M. Tolbert, "Control and protection of power electronics interfaced distributed generation systems in a customer-driven microgrid," in IEEE Power \&Energy Society General Meeting, pp.1-8, 2009.

[6] Alexis Kwasinki. "Grid-Microgrids Interconnection". Retrieved 20 June2016.

[7] J. Mitra, S. B. Patra, S. J. Ranade, and M. R. Vallem, "Reliability-Specified Generation and Distribution Expansion in Microgrid Architectures," WSEAS Transactions on Power Systems, vol. 1, no. 8, p. 1446, 2006.

[8] P. M. Costa and M. A. Matos, "Assessing the contribution of microgrids to the reliability of distribution networks," Electric Power Systems Research, vol. 79, no. 2, pp. 382-389, 2009.

[9] Z. Bie, P. Zhang, G. Li, B. Hua, M. Meehan, and X. Wang, "Reliability Evaluation of Active Distribution Systems Including Microgrids," IEEE Transactions on Power Systems, vol. 27, no. 4, pp. 2342-2350, Nov. 2012.

[10] Gautam, Prajjwal, et al. "Impact of the penetration levels of PV and synchronous machine based DG sources on the reliability of a microgrid." Electrical Power and Energy Conference (EPEC), 2017 IEEE. IEEE, 2017.

[11] A. K. Bas, S. Chowdhury, and S. P. Chowdhury, "Impact of Strategic Deployment of CHP-Based DERs on Microgrid Reliability," IEEE Transactions on Power Delivery, vol. 25, no. 3, pp. 1697-1705, July 2010.

[12] S. Kennedy, "Reliability evaluation of islanded microgrids with stochastic distributed generation," in Proc. IEEE Power \& Energy Society General Meeting, 2009, pp. 1-8, 26-30 July 2009.

[13] S. A. Arefifar and Y.A.-R.I. Mohamed, "DG Mix, Reactive Sources and Energy Storage Units for Optimizing Microgrid Reliability and Supply Security," IEEE Transactions on Smart Grid, vol. 5, no. 4, pp. 1835-1844, July 2014.

[14] Zheyuan Cheng, Jie Duan, Mo-Yuen Chow, "To Centralize or to Distribute: That Is the Question: A Comparison of Advanced Microgrid Management Systems", Industrial Electronics Magazine IEEE, vol. 12, pp. 6-24, 2018, ISSN 1932-4529.

[15] X. Xu, J.Mitra, T. Wang, and L. Mu, "Evaluation of Operational Reliability of a Microgrid Using a Short-Term Outage Model," IEEE Transactions on Power Systems, vol. 29, no. 5, pp. 2238-2247, Sept. 2014.

[16] X. Xu, J. Mitra, T. Wang, and L. Mu, "An Evaluation Strategy for Microgrid Reliability Considering the Effects of Protection System," IEEE Transactions on Power Delivery, vol. PP, no. 99, pp. 1-1. 
[17] M. A. Smith and S. Atcitty, "Power Electronics Reliability Analysis," Sandia National Laboratories, Albuquerque, New Mexico, Tech. Rep. SAND2009-8377, Dec. 2009.

[18] FIDES Guide 2009 Edition: A Reliability Methodology for Electronic Systems. (Sep. 2010) [Online]. Available: www.fides-reliability.org.

[19] M. Arifujjaman, M. T. Iqbal, and J. E. Quaicoe, "Reliability analysis of grid connected small wind turbine power electronics," Appl. Energy, vol. 86, no. 9, pp. 1617-1623, 2009.

[20] D. A. Murdock, J. E. R. Torres, J. J. Connors, and R. D. Lorenz, "Active thermal control of power electronic modules," IEEE Transactions on Industry Applications, vol. 42, no. 2, pp. 552-558, March-April 2006.

[21] S. Yang, D. Xiang, A. Bryant, P. Mawby, L. Ran, and P. Tavner, "Condition Monitoring for Device Reliability in Power Electronic Converters: A Review," IEEE Transactions on Power Electronics, vol. 25, no. 11, pp. 2734-2752, Nov. 2010.

[22] H. Wang, M. Liserre, F. Blaabjerg, P. de Place Rimmen, J. B. Jacobsen, T. Kvisgaard, and J. Landkildehus, "Transitioning to Physics-of-Failure as a Reliability Driver in Power Electronics," IEEE Journal of Emerging and Selected Topics in Power Electronics, vol. 2, no. 1, pp. 97-114, March 2014.

[23] M. Musallam, C. Yin, C. Bailey, and M. Johnson, "Mission Profile-Based Reliability Design and Real-Time Life Consumption Estimation in Power Electronics," IEEE Transactions on Power Electronics, vol. 30, no. 5, pp. 2601-2613, May 2015.

[24] S. E. De Leon-Aldaco, H. Calleja, and J. Aguayo Alquicira, "Reliability and Mission Profiles of Photovoltaic Systems: A FIDES Approach," IEEE Transactions on Power Electronics, vol. 30, no. 5, pp. 2578-2586, May 2015.

[25] K. Xie, Z. Jiang, and W. Li, "Effect of Wind Speed on Wind Turbine Power Converter Reliability," IEEE Transactions on Energy Conversion, vol. 27, no. 1, pp. 96-104, March 2012.

[26] Y. Song; B. Wang, "Survey on Reliability of Power Electronic Systems," IEEE Transactions on Power Electronics, vol. 28, no. 1, pp. 591-604, Jan. 2013.

[27] M. A. Masrur, "Penalty for fuel economy-System level perspectives on the reliability of hybrid electric vehicles during normal and graceful degradation operation," IEEE Syst. J., vol. 2, no. 4, pp. 476-483, Dec. 2008

[28] P. Wikstrom, L. A. Terens, and H. Kobi, "Reliability, availability, and maintainability of high-power variable-speed drive systems," IEEE Trans. Ind. Appl., vol. 36, no. 1, pp. 231-241, Jan./Feb. 2000

[29] D. Hirschmann, D.Tissen, S. Schroder, and R.W.DeDoncker, "Reliability prediction for inverters in hybrid electrical vehicles," IEEE Trans. Power Electron., vol. 22, no. 6, pp. 2511-2517, Nov. 2007

[30] S. S. Smater and A. D. Dominguez-Garcia, "A unified framework for reliability assessment of wind energy conversion systems," in Proc. Power Energy Soc. Gen. Meet., 2010, pp. 1-4.

[31] A. D. Dominguez-Garcia and P. T. Krein, "Integrating reliability into the design of fault-tolerant power electronics systems," in Proc. Power Electron. Spec. Conf., 2008, pp. 2665-2671.

[32] G. Petrone, G. Spagnuolo, R. Teodorescu, M. Veerachary, and M. Vitelli, "Reliability issues in photovoltaic power processing systems," IEEE Trans. Ind. Electron., vol. 55, no. 7, pp. 2569-2580, Jul. 2008.

[33] "Reliability prediction of electronic equipment," Department of Defense, Washington DC, Tech. Rep. MIL-HDBK-217F, Dec. 1991. 
[34] M. Pecht and K.Wen-Chang, "A critique of MIL-HDBK-217E reliability prediction methods," IEEE Trans. Rel., vol. 37, no. 5, pp. 453-457, Dec.1988.

[35] J. Jones and J. Hayes, "Estimation of system reliability using a "non-constant failure rate" model," IEEE Trans. Rel., vol. 50, no. 3, pp. 286-288, Sep. 2001.

[36] Xu, Xufeng, et al. "Evaluation of operational reliability of a microgrid using a short-term outage model." IEEE Transactions on Power Systems 29.5 (2014): 2238-2247.

[37] K. Xie, Z. Jiang, and W. Li, "Effect of Wind Speed on Wind Turbine Power Converter Reliability," IEEE Transactions on Energy Conversion, vol. 27, no. 1, pp. 96-104, March 2012.

[38] M. Liu, W. Li, C. Wang, R. Billinton, and J. Yu, "Reliability Evaluation of a Tidal Power Generation System Considering Tidal Current Speeds," IEEE Transactions on Power Systems, vol. PP, no. 99, pp. 1-10, Sept. 2015.

[39] H. Zhang and L. M. Tolbert, "Efficiency impact of silicon carbide power electronics for modern wind turbine full scale frequency converter," IEEE Trans. Ind. Electron., vol. 58, no. 1, pp. 21-28, 2011.

[40] F. Z. Peng, Y. W. Li, and L. M. Tolbert, "Control and protection of power electronics interfaced distributed generation systems in a customer-driven microgrid," in Proc. Power \& Energy Society General Meeting, 2009, pp.1-8, 26-30 July 2009.

[41] H. Zhang and L. M. Tolbert, "SiC's potential impact on the design of wind generation system," 2008 34th Annual Conference of IEEE IECON, pp. 2231-2235, 10-13 Nov. 2008.

[42] R. Billinton, R. N. Allan, Reliability Evaluation of Power Systems, New York: Springer, 1996.

[43] Y. Sun, P. Wang, L. Cheng, and H. Liu, "Operational reliability assessment of power systems considering condition-dependent failure rate," IET Generation, Transmission \& Distribution, vol. 4, no. 1, pp. 60-72, January 2010.

[44] T. Senjyu, S. Higa, and K. Uezato, "Future load curve shaping based on similarity using fuzzy logic approach," in IEE Proceedings - Generation, Transmission and Distribution, vol. 145, no. 4, pp. 375-380, Jul 1998.

[45] S. Sheng, "Report on wind turbine subsystem reliability-a survey of various databases." National Renewable Energy Laboratory, 2013.

[46] E. Collins, M. Dvorack, J. Mahn, M. Mundt, and M. Quintana, "Reliability and availability analysis of a fielded photovoltaic system," 2009 34th IEEE Photovoltaic Specialists Conference (PVSC), Philadelphia, PA, 2009, pp. 2316- 2321.

[47] M. Liu, W. Li, C. Wang, M. P. Polis, Y. L. Wang, and J. Li, "Reliability Evaluation of Large Scale Battery Energy Storage Systems," IEEE Transactions on Smart Grid, vol. PP, no. 99, pp. 1-11. 